\title{
C5a receptor signalling in dendritic cells controls the development of maladaptive Th2 and Th17 immunity in experimental allergic asthma
}

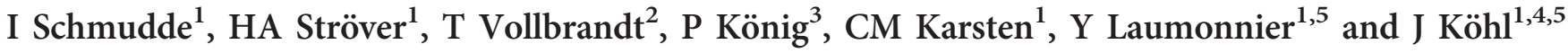

The pathways underlying dendritic cell (DC) activation in allergic asthma are incompletely understood. Here we demonstrate that adoptive transfer of ovalbumin-pulsed wild-type (wt) but not of C5a receptor-deficient $\left(\mathrm{C}^{2} \mathrm{aR}^{-{ }^{-}}{ }^{-}\right)$ bone marrow (BM)-derived DCs (BMDCs) induced mixed T helper type 2 (Th2)/Th17 maladaptive immunity, associated with severe airway hyperresponsiveness, mucus production, and mixed eosinophilic/neutrophilic inflammation. Mechanistically, antigen uptake, processing, and CD11b expression were reduced in C5aR ${ }^{-1-} \mathrm{BMDCs}$. Further, interleukin (IL)-1 $\beta,-6$, and -23 production were impaired resulting in reduced Th17 cell differentiation, associated with accelerated activated T-cell death in vitro and in vivo. Surprisingly, we found an increased frequency of $\mathrm{CD} 11 \mathrm{~b}^{\text {hi }} \mathrm{CD} 11 \mathrm{c}^{\mathrm{int}} \mathrm{Gr} 1^{+} \mathrm{F} 4 / 80^{+}$cells, expressing arginase and nitric oxide synthase in $\mathrm{C} 5 \mathrm{aR}^{-1-} \mathrm{BM}$ preparations. Intratracheal administration of ovalbumin-pulsed wt DCs and sorted CD11 b ${ }^{\text {hi }} \mathrm{CD} 11 \mathrm{c}^{\text {int }} \mathrm{Gr} 1^{+} \mathrm{F} 4 / 80^{+} \mathrm{C} 5 \mathrm{aR}^{-1}{ }^{-}$cells reduced Th2 immune responses in vivo. Together, we uncover novel roles for C5aR in Th17 differentiation, T-cell survival, and differentiation of a DC-suppressor population controlling Th2 immunity in experimental allergic asthma.

\section{INTRODUCTION}

Allergic asthma is a chronic inflammatory disease of the airways that is mainly driven by maladaptive $\mathrm{T}$ helper type 2 (Th2) immune responses. Several reports have demonstrated that pulmonary dendritic cells (DC) have a key role in the uptake and processing of aeroallergens and the differentiation of naive $\mathrm{CD} 4{ }^{+} \mathrm{T}$ cells into allergen-specific Th2 effector cells. ${ }^{1}$ Under steady state conditions, CD11 $\mathrm{c}^{\text {hi }}$ conventional DCs (cDC) and CD11 $c^{\text {lo }}$ plasmacytoid DCs (pDC) reside in the lung. cDCs can be further subdivided into $\mathrm{CD} 11 \mathrm{~b}^{+} \mathrm{CD} 103^{-}$and

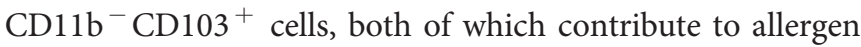
uptake, processing, and activation of $\mathrm{CD} 4^{+} \mathrm{T}$ cells. The exact role of the two $\mathrm{CDC}$ populations in Th-cell differentiation remains elusive. Two reports suggest that $\mathrm{CD} 11 \mathrm{~b}^{+} \mathrm{CD} 103^{-}$ DCs preferentially promote differentiation of Th2 effector cells, ${ }^{2,3}$ whereas $\mathrm{CD} 11 \mathrm{~b}^{-} \mathrm{CD} 103^{+}$DCs induce Th1 and Th17 effector cells. ${ }^{3}$ By contrast, Nakano et al. ${ }^{4}$ found that CD11b ${ }^{+}$ $\mathrm{CD}_{103}{ }^{-}$cells preferentially drive Th1 and $\mathrm{CD} 11 \mathrm{~b}^{-} \mathrm{CD} 103^{+}$ DCs Th2 differentiation. The function of pDCs is to control and protect the lung environment from unwanted $\mathrm{cDC}$-instructed maladaptive immunity. ${ }^{5,6}$ The exact mechanisms underlying the activation of the distinct DC subpopulations under steady state and inflammatory conditions are still incompletely understood. Evidences from epidemiological studies and experimental asthma models suggest that environmental factors, including the exposure to inhaled allergens or pollutants, and microbial infections are critical. The emerging paradigm is that environmental and microbial molecules activate conserved humoral and cellular sensing systems of the innate immune system and that the integration of such signals defines the activation program of pulmonary DCs, i.e., to keep pulmonary tolerance or to initiate and drive adaptive immune responses. ${ }^{1}$

Microbial components within aeroallergens such as lipopolysaccharide can activate the complement system and generate the anaphylatoxins C3a and C5a. Moreover, allergen-derived proteases can directly generate $\mathrm{C} 3 \mathrm{a}$ and $\mathrm{C} 5 \mathrm{a}$ without activation of the entire complement cascade. ${ }^{7}$ Indeed, C3a and C5a have been found in the

\footnotetext{
${ }^{1}$ Institute for Systemic Inflammation Research, University of Lübeck, Lübeck, Germany. ${ }^{2}$ Clinical and Experimental Research Facility, University of Lübeck, Lübeck, Germany. ${ }^{3}$ Institute for Anatomy, University of Lübeck, Lübeck, Germany. ${ }^{4}$ Division of Cellular and Molecular Immunology, Cincinnati Children's Hospital and University of Cincinnati, College of Medicine, Cincinnati, Ohio, USA. ${ }^{5}$ Y Laumonnier and J Köhl shared supervision of this work. Correspondence: J Köhl (joerg.koehl@uksh.de)
} 
airways under steady state conditions and in allergic inflammation. ${ }^{6,8}$ Interestingly, C5a exerts a dual role in allergic asthma. Pharmacological targeting of the $\mathrm{C} 5 \mathrm{aR}$ during allergen sensitization with house-dust mite (HDM) extract or ovalbumin (OVA) $)^{6,9}$ or genetic deletion of $\mathrm{C}^{9-11}$ or the $\mathrm{C}^{9} \mathrm{aR}^{6,9}$ results in an increased allergic phenotype with high Th2 and Th17 cytokine production, suggesting a protective role for $\mathrm{C} 5 \mathrm{a}$ during allergen priming. By contrast, blocking the $\mathrm{C} 5 \mathrm{aR}$ during the allergic effector phase attenuates the allergic phenotype. ${ }^{6,12,13}$ The increased maladaptive Th2 response following C5aR targeting is associated with an increased ratio of cDCs vs. pDCs and a decreased expression of B7$\mathrm{H} 1$ and $\mathrm{B} 7-\mathrm{DC}$ on $\mathrm{pDCs},{ }^{14}$ suggesting that C5a may directly regulate DC activity in the lung through C5aR activation. In support of this view, $\mathrm{C} 5 \mathrm{aR}^{-1-}$ spleen-derived $\mathrm{cDCs}$ that were stimulated with OVA in the presence of the TLR2 ligand Pam $3 \mathrm{Cys}^{15}$ or $\mathrm{C}_{5} \mathrm{aR}^{-1-}$ bone marrow $(\mathrm{BM})$-derived DCs that were stimulated with HDM extract ${ }^{9}$ produce more IL-23 than wt DCs.

To directly assess the impact of $\mathrm{C} 5 \mathrm{aR}$ signaling in $\mathrm{cDCs}$ for the development of maladaptive Th2 and Th17 immunity, we have injected OVA-pulsed granulocyte macrophages colony-stimulating factor (GM-CSF)-differentiated BMDCs from C5aR-deficient mice intratracheally (IT) into wt BALB/c mice. Surprisingly, $\mathrm{C} 5 \mathrm{aR}^{-1-} \mathrm{cDCs}$ failed to promote a typical Th2 response, which was associated with a decreased potency of antigen processing and $\mathrm{CD} 11 \mathrm{~b}$ expression in vitro. Further, $\mathrm{C}_{\mathrm{a}} \mathrm{R}^{-1-} \mathrm{cDC}$-activated $\mathrm{CD}^{+}{ }^{+} \mathrm{T}$ cells suffered from accelerated cell death associated with decreased expression of the prosurvival protein $\mathrm{Bcl}-2$ and upregulation of the proapoptotic proteins BimL and BimEL. In line with this finding, we found a decreased frequency of pulmonary OVA-specific $\mathrm{CD} 4{ }^{+} \mathrm{T}$ cells 9 days after adoptive transfer of $\mathrm{C}_{5} \mathrm{aR}^{-1-} \mathrm{BM}$ DCs. Finally, we observed a higher

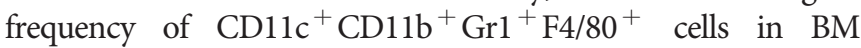
cultures of $\mathrm{C}_{\mathrm{a}} \mathrm{R}^{-1-}$ mice resembling myeloid-derived suppressor cells (MDSC). Importantly, MDSC from $\mathrm{C} 5 \mathrm{aR}^{-1-}$ mice expressed higher levels of nitric oxide synthase 2 (NOS2) than MDSC from wt mice in vitro. Further, the functional properties of MDSC from wt and $\mathrm{C}_{5} \mathrm{R}^{-1-}$ mice were qualitatively and quantitatively different with regard to their ability to block Th2, Th17, and Th1 maladaptive immune responses in vivo.

\section{RESULTS \\ Impaired allergen uptake of BMDCs from C5aR-deficient mice}

DCs are sentinels of the innate immune system that sample antigens, process, and present them through major histocompatibility complex (MHC) class II molecules to T cells. We first compared the potencies of BMDCs from wt and $\mathrm{C} 5 \mathrm{aR}^{-1-}$ mice to take up the model antigen OVA. For this purpose, we incubated BMDCs with fluorescein isothiocyanate (FITC)conjugated OVA (FITC-OVA) and determined the fluorescence intensity within $\mathrm{CD} 11 \mathrm{~b}^{+} \mathrm{CD} 11 \mathrm{c}^{+}$cells at different time points by flow cytometry (Figure 1a). As shown in Figure 1b, we found an increased fluorescence signal in wt DCs as early as $30 \mathrm{~min}$ after FITC-OVA administration, which reached a plateau after $180 \mathrm{~min}$ incubation. DCs from $\mathrm{C}_{5} \mathrm{aR}^{-/-}$animals showed a similar kinetic. However, the fluorescence signal was always lower in $\mathrm{C} 5 \mathrm{aR}^{-1-}$ DC. At the end of the observation period (240 min), the fluorescence signal in $\mathrm{C}^{\mathrm{a}} \mathrm{R}^{-1-}$ DCs was decreased by $70 \%$ as compared with that in wt DCs (from $931 \pm 28$ to $289 \pm 131$ ). By contrast, antigen uptake of C3aR or C5L2-deficient DCs was similar to wt DCs (see Supplementary Figure S1 online).

The signal of FITC-OVA is $\mathrm{pH}$ sensitive and can be quenched by acidic $\mathrm{pH}$. To avoid this problem and to assess the impact of C5aR deficiency on antigen processing, we used DQOVA. Upon proteolytic degradation, photostable and $\mathrm{pH}$ insensitive green fluorescent peptides are released from DQOVA, reflecting antigen processing. Interestingly, we observed a substantial difference of the initial antigen processing between wt and $\mathrm{C}_{5} \mathrm{aR}^{-1-}$ DCs. Already 15 min after allergen incubation, $\mathrm{C}_{\mathrm{a}} \mathrm{R}^{-1-} \mathrm{DCs}$ showed an increase in the fluorescence signal, which was absent in wt DCs (Figure 1b). Allergen processing in wt DCs became visible after $30 \mathrm{~min}$ but was still lower than in $\mathrm{C} 5 \mathrm{aR}^{-1-}$ DCs. However, during the next hour (60-120 min after allergen administration), the $\triangle \mathrm{MFI}$ (mean fluorescent intensity) signal in wt DCs increased from 502 to 1,818 , whereas it increased only to 946 in C5aR ${ }^{-1-}$ DCs. At the end of the observation period $(240 \mathrm{~min})$, it reached 2,391 \pm 99 in wt DCs but only $1,322 \pm 324$ in $\mathrm{C} 5 \mathrm{aR}^{-1-}$ DCs. Thus, $\mathrm{C}_{5} \mathrm{aR}^{-1-}$ DCs start processing OVA quicker than wt DCs early after allergen uptake. However, $60 \mathrm{~min}$ after allergen incubation, most of the wt DCs homogenously process the OVA with a high pace, resulting in a dominant population of DQ-OVA $^{\text {hi }}$ cells and only a minor fraction of DQ-OVA ${ }^{\text {lo }}$ cells (Figure 1c). By contrast, two populations of $\mathrm{C}^{2} \mathrm{aR}^{-1-}$ DCs can be differentiated, one that processes DQ-OVA with a similar pace as wt DCs and a second population that processes DQOVA at a much lower pace.

The process of OVA uptake and processing is complex and involves pinocytosis and receptor-mediated endocytosis. ${ }^{16}$ Blocking of scavenger receptor-mediated endocytosis by poly-inosinic acid resulted in $85 \%$ or $75 \%$ reduction of the

Figure $1 \mathrm{C}^{2} \mathrm{aR}^{-1-}$ dendritic cells (DCs) show reduced antigen uptake. (a) Experimental design. Briefly, bone marrow (BM) cells were isolated from wt $\mathrm{BALB} / \mathrm{c}$ and $\mathrm{C} 5 \mathrm{aR}^{-1-}$ mice and differentiated for 10 days in the presence of $20 \mathrm{ng} \mathrm{ml}^{-1}$ granulocyte macrophages colony-stimulating factor (GM-CSF). On day $10,3 \times 10^{5} \mathrm{DCs}$ were incubated for different periods with either fluorescein isothiocyanate (FITC)- or DQ-OVA (ovalbumin) to assess antigen uptake or processing. Cells were washed, stained with anti-CD11c-APC and anti-CD11b-APC-Cy7 and analyzed by flow cytometry. Cells incubated at $4{ }^{\circ} \mathrm{C}$ served as controls. As a measure of uptake/processing the $\triangle \mathrm{MFI}$ (mean fluorescent intensity) was calculated. (b) Determination of antigen uptake using FITC-OVA (left panel) and antigen uptake and processing using DQ-OVA (right panel). (c) Kinetic of antigen processing by wild-type (wt) or $\mathrm{C} 5 \mathrm{aR}^{-1-}$ DCs. Histograms are representative of three independent experiments. (d) To differentiate between pinocytosis and scavenger-mediated endocytosis, BM cells were treated with dimethylamiloride (DMA) to block pinocytosis and poly-inosinic acid (polyl) to block scavenger-mediated endocytosis $30 \mathrm{~min}$ before incubation with either FITC-OVA (left panel) or DQ-OVA (right panel) for $240 \mathrm{~min}$. Values shown are the mean \pm s.e.m.; $n \geqslant 3$ per group, ${ }^{\star} P<0.05,{ }^{\star \star} P<0.01,{ }^{\star \star \star} P<0.001$. 
FITC-OVA or the DQ-OVA signal suggesting that this endocytosis pathway is critical for OVA uptake (Figure 1d) both in wt and $\mathrm{C}_{5} \mathrm{aR}^{-1-}$ DCs. Inhibition of pinocytosis by dimethylamiloride reduced the FITC-OVA signal by $70 \%$ in wt or $50 \%$ in $\mathrm{C} 5 \mathrm{aR}^{-1-}$ DCs but had only a minor impact on the DQ-OVA signal in wt and $\mathrm{C} 5 \mathrm{aR}^{-1-}$ DCs. These data suggest
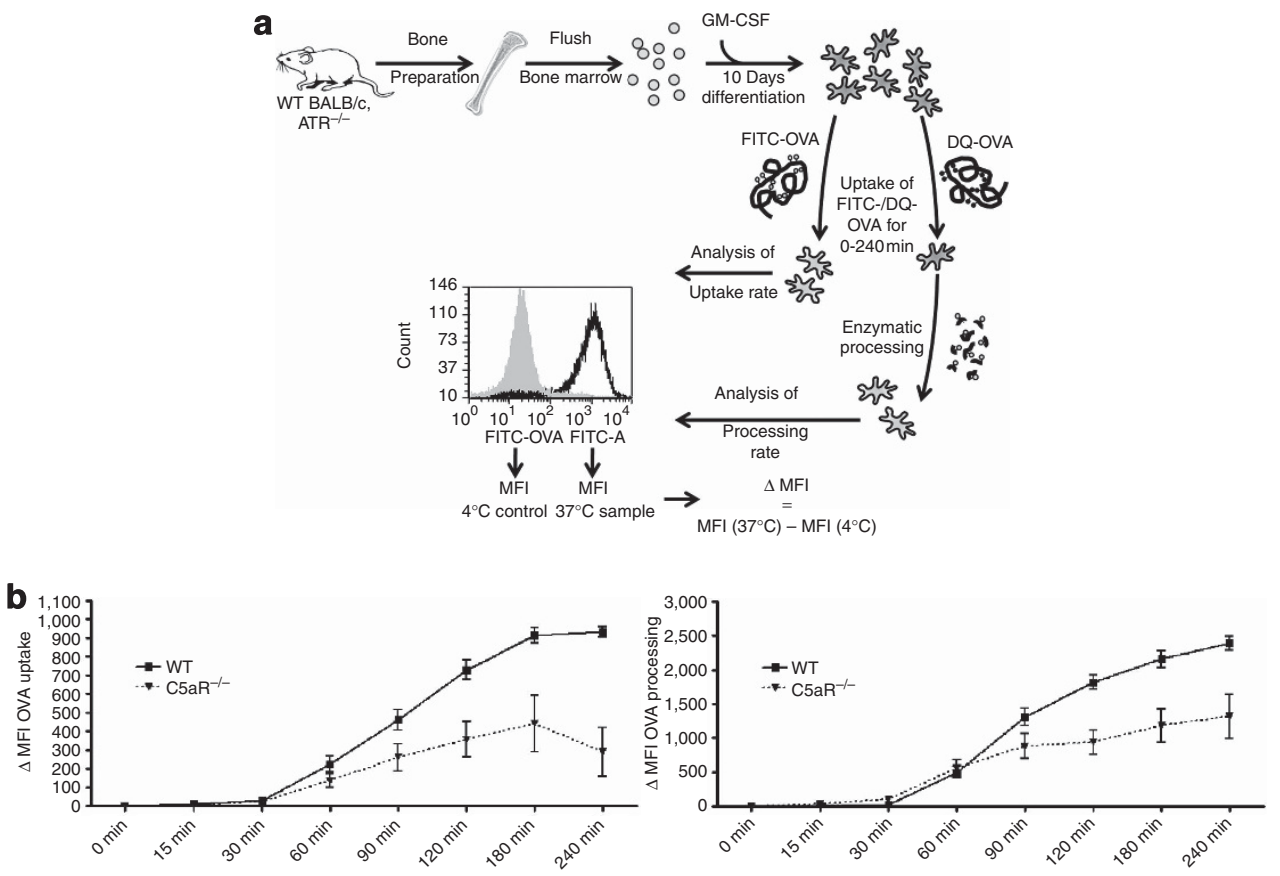

C
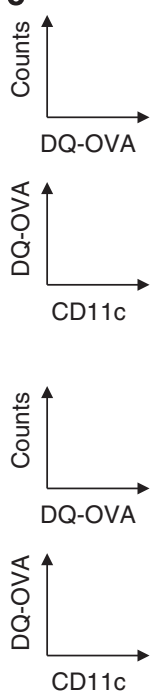
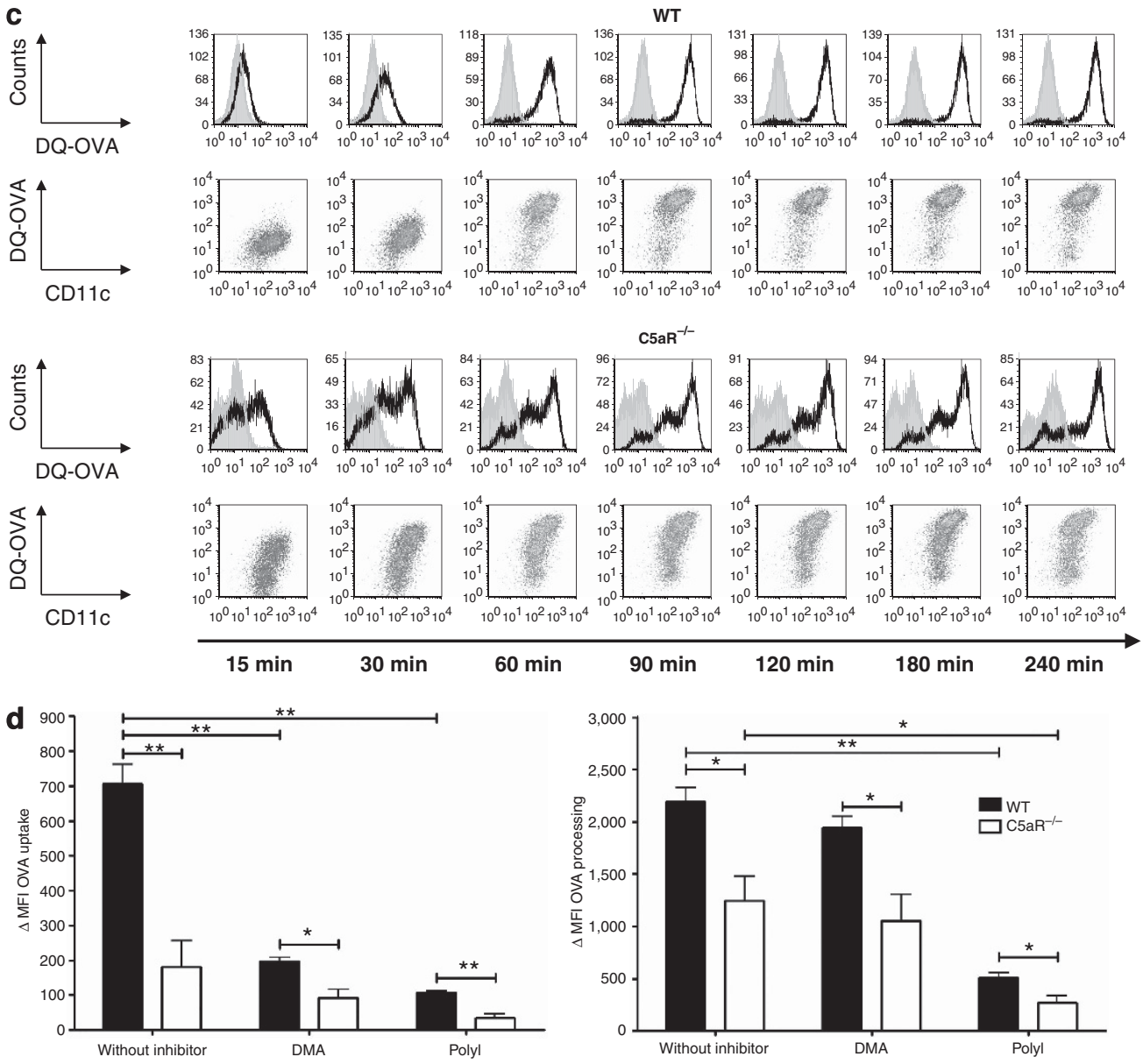
that the lack of $\mathrm{C} 5 \mathrm{aR}$ has no preferential impact on a particular pathway of OVA uptake and processing.

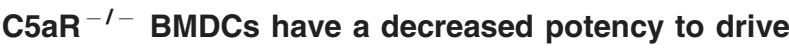 experimental allergic asthma}

The impaired allergen processing of $\mathrm{C}_{\mathrm{a}} \mathrm{R}^{-1-} \mathrm{DCs}$ encouraged us to assess the potency of OVA-pulsed C5aR ${ }^{-1-}$ DCs to drive experimental allergic asthma. Previous studies have shown that IT administration of BMDCs results in a strong asthmatic phenotype. ${ }^{17-19}$ GM-CSF-differentiated wt and C5aR ${ }^{-1-}$ BMDCs were pulsed overnight with DQ-OVA and transferred IT to wt BALB/c-recipient mice (Figure 2a). Ten days later, mice were challenged IT with $1.5 \%$ OVA. Animals transferred with DQ-OVA-pulsed wt DCs showed a clear asthmatic phenotype, characterized by marked airway hyperresponsiveness (AHR; Figure 2b) associated with strong eosinophilic and neutrophilic airway inflammation (Figure 2c). Histological examination of the airways confirmed the massive recruitment of inflammatory cells (Figure 2d) and provided evidence for strong mucus production within the bronchi (Figure 2e). In addition to airway reactivity and inflammation, we also determined the development of maladaptive T-cell responses. As shown in Figure 2f, we found a dominant Th2 cytokine profile signature when lung cells were restimulated with OVA, associated with IL-17A and interferon- $\gamma($ IFN- $\gamma)$ production. By contrast, transfer of DQOVA-pulsed DCs from $\mathrm{C}_{5} \mathrm{aR}^{-1-}$ mice failed to drive a strong asthmatic phenotype as evidenced by a significantly lower airway resistance, a markedly decreased airway eosinophilia, and a strong decrease in mucus production (Figure $\mathbf{2 b}-\mathbf{e}$ ). We also observed a trend toward decreased neutrophil numbers. The most striking finding was that the adoptive transfer of DQOVA-pulsed C5aR ${ }^{-1-}$ DCs resulted in marginal Th2 cytokine production, which was at the level of unpulsed wt or $\mathrm{C}_{5} \mathrm{aR}^{-1-}$ DCs (Figure 2f). Further, the IL-17A production decreased by $40 \%$ (from $1,698 \pm 269$ to $1,018 \pm 149 \mathrm{pg} \mathrm{ml}^{-1}$; unpulsed $393 \pm 106 \mathrm{pg} \mathrm{ml}^{-1}$ ). The tumor-necrosis factor- $\alpha$ (TNF- $\alpha$ ) and the IFN- $\gamma$ production were not affected by the absence of $\mathrm{C} 5 \mathrm{aR}$. Taken together, these data suggest a critical role for $\mathrm{C} 5 \mathrm{aR}$ signaling in BMDC-mediated induction of experimental allergic asthma.

As shown in Figure 1c, $\mathrm{C} 5 \mathrm{aR}^{-1-}$ DCs suffer from decreased OVA processing resulting in DQ-OVA ${ }^{\text {hi }}$ and DQ-OVA ${ }^{\text {lo }}$ populations, whereas most of the wt DCs are DQ-OVA ${ }^{\text {hi }}$. We wondered whether the failure of $\mathrm{C}_{5} \mathrm{aR}^{-1-} \mathrm{DCs}$ driving a pulmonary Th2 response might result from the decreased frequency of DQ-OVA ${ }^{\text {hi }}$ cells. To test this hypothesis, we sorted wt and C5aR ${ }^{-1-}$ DQ-OVA ${ }^{\text {hi }}$ and DQ-OVA ${ }^{\text {lo }}$ cells and injected the two populations IT into BALB/c wt mice (Figure 3a). In line with a previous report, ${ }^{4}$ we found that DCs with a low antigen uptake (DQ-OVA ${ }^{\text {lo }}$ cells) were more potent asthma inducers than DCs with a high antigen uptake (DQ-OVA ${ }^{\text {hi }}$ cells). AHR, airway inflammation, mucus production, and Th2 cytokine production were significantly higher in response to transfer of wt DQ-OVA ${ }^{\text {lo }}$ cells as compared with wt DQ-OVA ${ }^{\text {hi }}$ cells (Figure 3a-e). We also found a trend toward higher
IL-17A production (Figure 3f) in the wt DQ-OVA ${ }^{\text {lo }}$ group, although this difference did not reach the level of statistical relevance. TNF- $\alpha$ and IFN- $\gamma$ levels were similar in both the groups. Similar to what we had observed with unsorted DC populations (Figure 2), C5aR deficiency resulted in decreased AHR, airway inflammation, mucus production, Th2, and Th17 cytokine production, whereas the IFN- $\gamma$ levels were comparable in the wt and $\mathrm{C}_{5} \mathrm{aR}^{-1-}$ DQ-OVA ${ }^{\text {lo }}$ groups. Together, the decreased potency of $\mathrm{C}_{\mathrm{a}} \mathrm{R}^{-1-} \mathrm{DCs}$ to drive an allergic phenotype cannot be assigned to the higher frequency of DQ-OVA ${ }^{\text {lo }}$ cells, as such cells were more potent to drive experimental allergic asthma than their DQ-OVA ${ }^{\text {hi }}$ counterparts.

\section{$\mathrm{C5aR}^{-1-}$ DCs express less CD11b and produce less Th17- cell-promoting cytokines in vitro}

In search for mechanisms that may account for the decreased potency of $\mathrm{C} 5 \mathrm{aR}^{-1-}$ DCs to promote allergic asthma, we determined the frequency and the expression levels of $\mathrm{CD} 1 \mathrm{~b}$, MHC class II, CD40, CD80, and CD86 on CD11c ${ }^{+}$wt and $\mathrm{C} \mathrm{aR}^{-1-} \mathrm{DCs}$ before and $24 \mathrm{~h}$ after OVA incubation in vitro. As expected, $90 \%$ of wt and C5aR ${ }^{-1-}$ DCs co-expressed the $\mathrm{CD} 11 \mathrm{c}$ and the $\mathrm{CD} 11 \mathrm{~b}$ markers before and after the OVA pulse. $\mathrm{CD} 11 \mathrm{c}^{+} \mathrm{CD} 11 \mathrm{~b}^{+} \mathrm{DCs}$ were negative for the macrophage/DC progenitor markers CD115, CD117, CD135, and CX3CR1 (data not shown). Between $25-50 \%$ of the unpulsed CD11c ${ }^{+}$ $\mathrm{CD}_{11 \mathrm{~b}^{+}}$wt and $\mathrm{C}_{\mathrm{aR}}{ }^{-1-}$ DCs expressed the co-stimulatory molecules CD80, CD86, and CD40, which increased significantly after OVA incubation (Figure $4 \mathbf{4 a}, \mathbf{b}$ ). Interestingly, the frequency of MHC-II ${ }^{+}$cells was significantly higher (75\%) in $\mathrm{C}^{2} \mathrm{aR}^{-1-}$ DCs than in wt DCs (20\%). OVA stimulation increased the frequency of $\mathrm{MCH}-\mathrm{II}^{+}$cells in both the DC populations to almost $100 \%$. Although almost all the DCs from wt and $\mathrm{C} 5 \mathrm{aR}^{-1-}$ mice were $\mathrm{CD} 11 \mathrm{~b}^{+}$, we found a significantly lower expression of CD11b on resting and OVA-pulsed DCs from $\mathrm{C}_{\mathrm{a}} \mathrm{aR}^{-1-}$ origin. Further, the higher frequency of MHC- $-\mathrm{II}^{+}$DCs in resting BM cultures from $\mathrm{C} \mathrm{aR}^{-1-}$ mice was associated with higher MHC-II expression. Although the frequency of $\mathrm{MHC}^{-\mathrm{II}^{+}}$DCs was similar in BM cultures from OVA-activated wt and C5aR, the expression levels were still somewhat higher in $\mathrm{C} 5 \mathrm{aR}^{-1-} \mathrm{DCs}$. The increased frequency of $\mathrm{CD} 80^{+}, \mathrm{CD} 86^{+}$, or $\mathrm{CD} 40^{+} \mathrm{DCs}$ in wt and $\mathrm{C} 5 \mathrm{aR}^{-1-}$ mice after OVA incubation was associated with and increased expression level of the costimulatory molecules (Figure 4c).

Next, we determined the production of cytokines that are critical for the differentiation of Th1, Th17, and regulatory T cells, such as IL-12p40, IL-12p70, IL-1 $\beta$, IL-6, IL-23, IL-33, and TGF- $\beta$ (Figure 4d). Except for TGF- $\beta$, unpulsed wt or $\mathrm{C}_{5} \mathrm{aR}^{-1-}$ DCs did not produce any of such cytokines. The TGF- $\beta$ production was lower in $\mathrm{C} 5 \mathrm{aR}^{-1-} \mathrm{DCs}$ as compared with wt DCs. By contrast, OVA stimulation resulted in significant production of all of the cytokines except of TGF- $\beta$, the levels of which were unchanged. Importantly, $\mathrm{C} \mathrm{aR}^{-1-} \mathrm{DCs}$ produced significantly less Th17-inducing cytokines IL-1 $\beta$, IL-6, and IL-23 (Figure 4d). Last but not the least, we found a minor increase in IL-12p70 production in the 

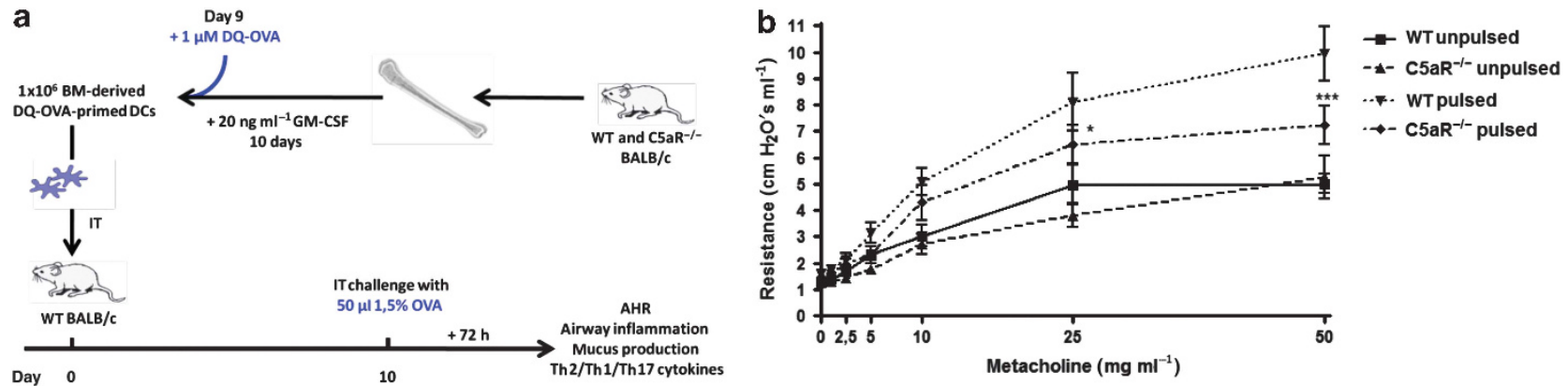

c
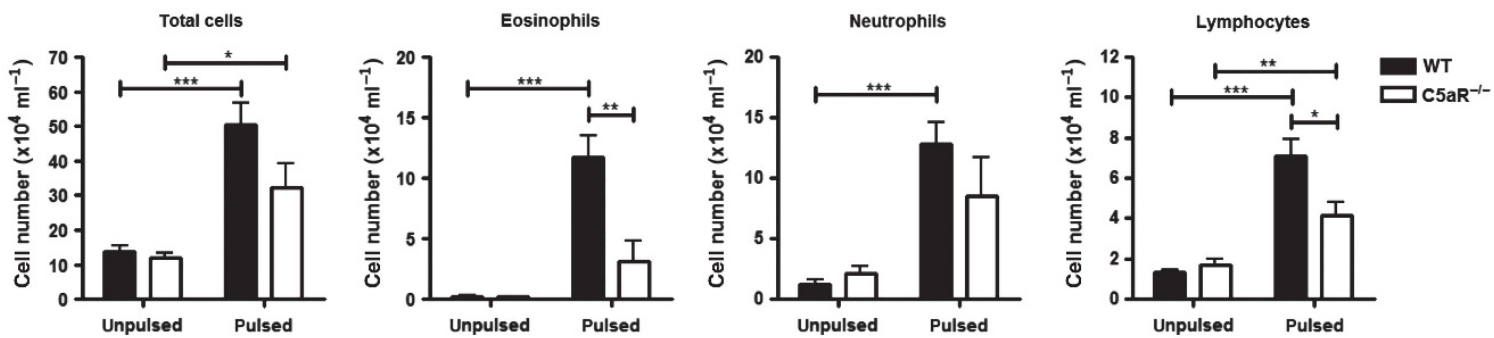

d
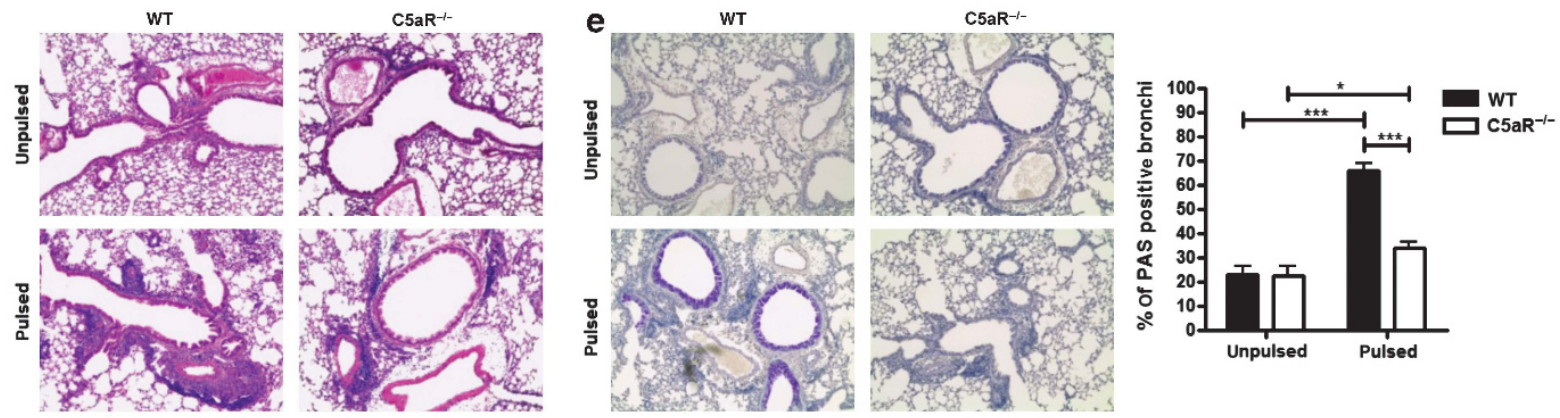

f
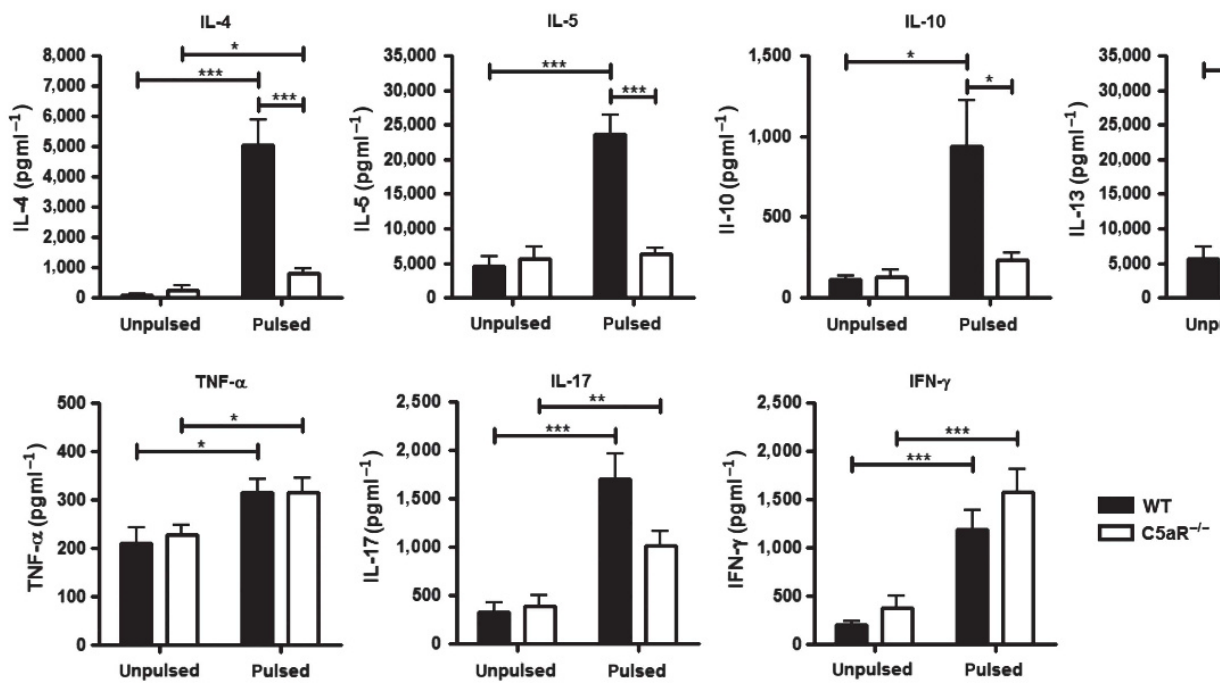

Figure 2 Adoptive transfer of $\mathrm{C} \mathrm{aR}^{-1-}$ dendritic cells (DCs) results in a reduced asthmatic phenotype. (a) Experimental design. Briefly, bone

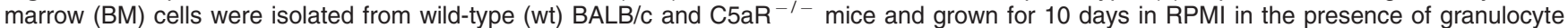
macrophages colony-stimulating factor (GM-CSF). On day 9, DCs were pulsed overnight with $1 \mu \mathrm{m}$ DQ-OVA or with phosphate-buffered saline. The next day, $1 \times 10^{6}$ unpulsed or pulsed DCs were administered intratracheally (IT) into BALB/c wt recipients. After 10 days, recipient mice were challenged IT with 1.5\% ovalbumin (OVA). Seventy-two hours after the injection, airway responsiveness was determined. Subsequently bronchoalveolar lavage (BAL) fluid, lung cells, and tissues were collected for further analysis. BALB/c mice receiving unpulsed DCs served as controls. (b) Airway hyperresponsiveness (AHR) in response to IT administration of metacholine measured as airway resistance using Flexivent. (c) Total and differential cell counts in BAL fluid. (d) Histological examination of airway inflammation. Sections were stained with hematoxylin and eosin (original magnification $\times 200$ ).

(e) Histological examination of goblet cell hyperplasia. Sections were stained with periodic acid-Schiff for mucus production (original magnification

$\times 200$ ). Mucus producing airways are plotted relative to all analyzed airways (right panel). (f) Cytokine profile of pulmonary cells harvested $72 \mathrm{~h}$ after OVA challenge. Supernatants were collected $72 \mathrm{~h}$ after in vitro cell culture. Values shown are the mean \pm s.e.m.; $n=9-10$ per group, ${ }^{\star} P<0.05,{ }^{\star \star} P<0.01$, ${ }^{\star \star \star} P<0.001$. IFN, interferon; IL, interleukin; Th, T helper; TNF, tumor-necrosis factor. 
a

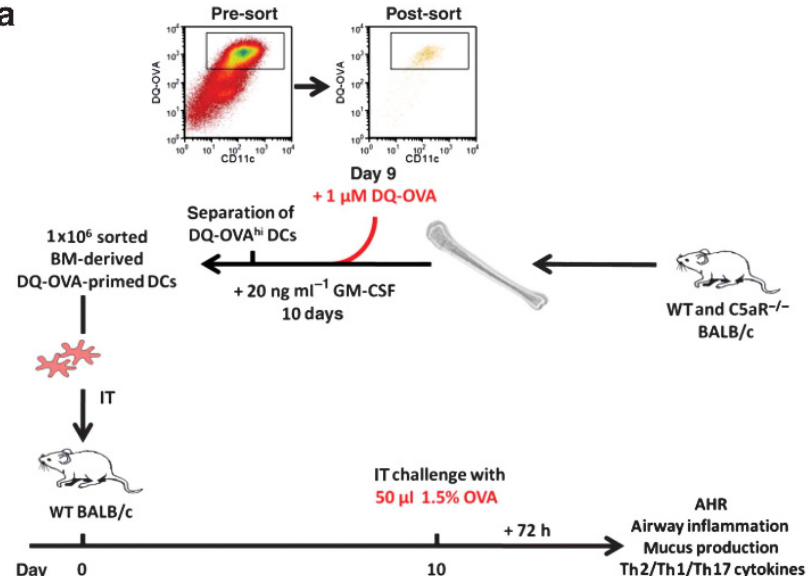

b

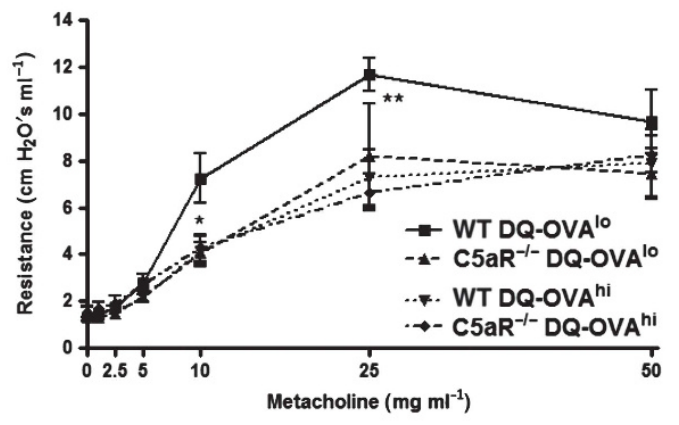

c

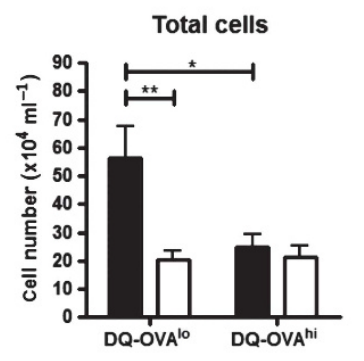

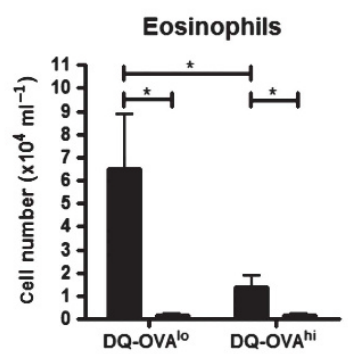
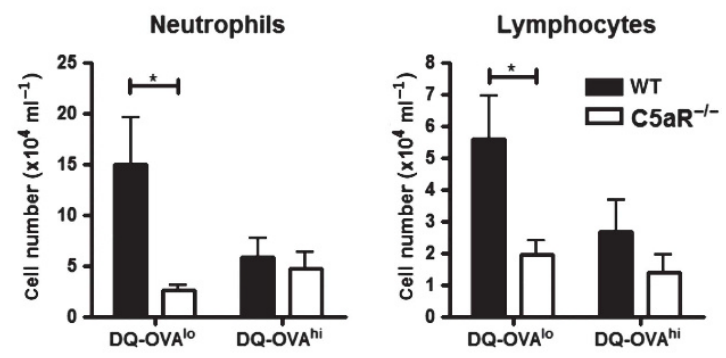

d
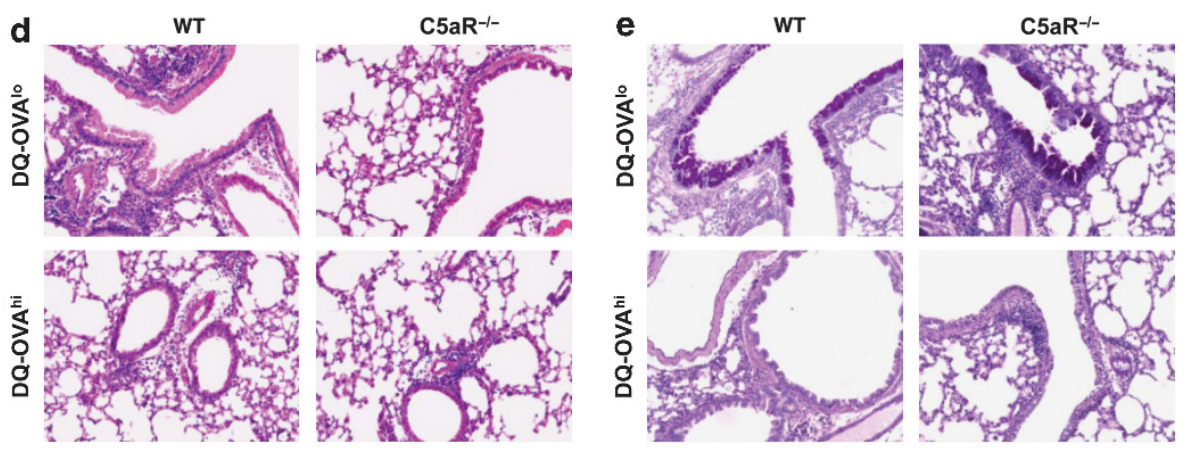

$\mathrm{C}^{\mathrm{a}} \mathrm{R}^{-1-}$
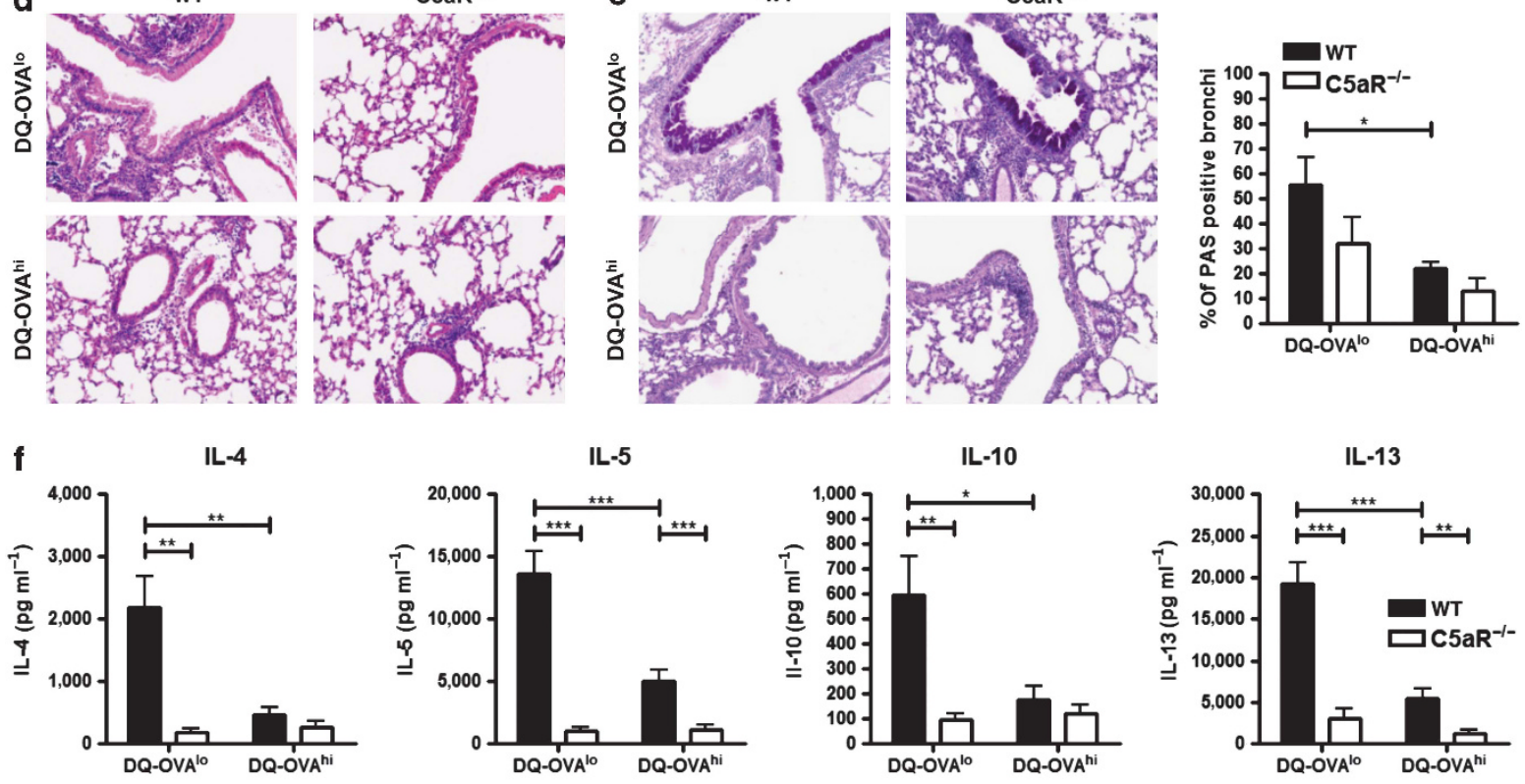

TNF- $\alpha$

IL-17
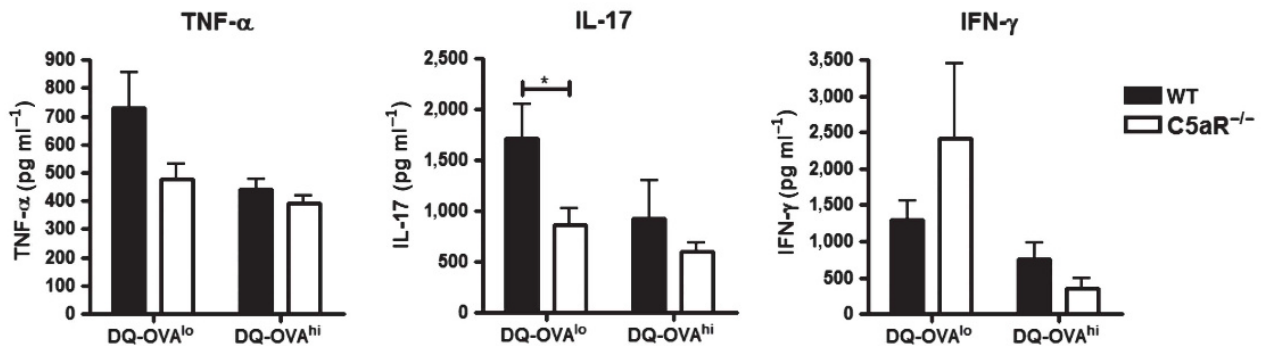
C5aR ${ }^{-1-}$ DCs as compared with wt DCs. Expression of IL-33 was slightly above the detection limit of the assay and not affected by the lack of C5aR.

\section{$\mathrm{C5aR}^{-1-}$ DCs have an impaired ability to drive Th1- and Th17-cell differentiation and accelerate activated CD4 ${ }^{+}$ T-cell death}

In the next step, we did setup co-cultures of OVA-stimulated DCs with OVA T-cell receptor (TCR)-transgenic DO11.10 $\mathrm{CD}^{+}{ }^{+} \mathrm{T}$ cells from RAG2-deficient mice. First, we assessed the ability of wt and $\mathrm{C} 5 \mathrm{aR}^{-1-}$ DCs to regulate T-cell proliferation. For this purpose, DCs were stimulated with OVA in the presence of carboxyfluorescein diacetate succinimidyl ester (CFSE)-labeled $\mathrm{CD}^{+}{ }^{+} \mathrm{T}$ cells for 4 days. As expected, $\mathrm{T}$ cells co-cultured with wt cells strongly proliferated as evidenced by the decrease of the CFSE signal over time. C5aR ${ }^{-1-}$ DCs were equally potent in driving $\mathrm{CD} 4^{+} \mathrm{T}$-cell proliferation (Figure 5a). Next, we assessed the ability of wt and $\mathrm{C}_{5} \mathrm{aR}^{-1-}$ DCs to drive allergen-specific differentiation of naive $\mathrm{CD} 4^{+} \mathrm{T}$ cells. After 4 days of co-culture, wt DCs promoted the production of the Th2 cytokines IL-4, IL-10, and IL-13, the Th17 cytokine IL-17A, and the Th1 cytokine IFN- $\gamma$ (Figure 5b). We found similar levels of Th2 cytokines in $\mathrm{C}^{2} \mathrm{aR}^{-1-} \mathrm{DC}$ cocultures. By contrast, IL-17A production was significantly reduced in $\mathrm{C} 5 \mathrm{aR}^{-1-} \mathrm{DC}$ co-cultures. As described before, IFN- $\gamma$ production was also reduced. ${ }^{15,20,21}$ These data are in line with the decreased IL-17A production associated with the decreased neutrophilic airway inflammation that we had observed after adoptive transfer of $\mathrm{C}_{5} \mathrm{aR}^{-1-}$ DCs into $\mathrm{BALB} / \mathrm{c}$ mice (Figures 2f and 3f). By contrast, $\mathrm{C} 5 \mathrm{aR}^{-1-}$ DCs are perfectly suited to drive Th2 effector cell differentiation in vitro, suggesting that the failure of $\mathrm{C}_{\mathrm{a}} \mathrm{R}^{-1-} \mathrm{DCs}$ to promote Th2 cytokine production in vivo does not result from a defect to initiate Th2-cell differentiation.

Following the clonal expansion and effector T-cell differentiation in response to DC-mediated activation, most of the T cells are deleted by apoptosis and only a few cells become memory T cells. ${ }^{22}$ To assess apoptotic deletion of effector T cells, we first determined the frequency of $\mathrm{DAPI}^{+}\left(4^{\prime}, 6-\right.$ diamidino-2-phenylindole) $\mathrm{CD} 4{ }^{+}$T cells on days 4 and 7. As expected, on day 4, only a minor fraction of CD4 T cells was apoptotic (data not shown). On day 7, $30 \%$ of the T cells from the $\mathrm{C}_{5} \mathrm{aR}^{-1-} \mathrm{DC}$ co-culture but only $8 \%$ from the wt $\mathrm{DC}$ coculture were $\mathrm{DAPI}^{+}$(Figure 5c). The decreased survival of T cells in the $\mathrm{C}_{\mathrm{aR}} \mathrm{aR}^{-1-} \mathrm{DC}$ co-culture on day 7 was associated with a significant decrease in IL-2 (Figure 5d) and a six or threefold increase in the two isoforms of the pro-apoptotic molecules B-cell lymphoma 2 (BCL-2)-interacting mediator of cell death (Bim) BimL and BimEL (Figure 5e). We found no impact on p53-upregulated modulator of apoptosis (Puma) expression, which can cooperate with Bim in activated T-cell apoptosis. ${ }^{23}$ Moreover, we observed a threefold decrease in the pro-survival molecule Bcl-2 in C5aR ${ }^{-1-}$ DC co-cultures. By contrast, we found no production of BCL- $\mathrm{X}_{\mathrm{L}}$ (data not shown). These data indicate that the signals provided by $\mathrm{C}_{5} \mathrm{aR}^{-1-} \mathrm{DCs}$ to OVA-specific T cells are sufficient to promote their initial clonal expansion and differentiation into Th2 effector cells. However, in contrast to the wt DCs, $\mathrm{C}_{\mathrm{a}} \mathrm{R}^{-1-}$ DCs drive OVAspecific $\mathrm{T}$ cells into the contraction phase at an earlier time point.

\section{$\mathrm{C5aR}^{-1-}$ DCs have an impaired ability to induce stable $\mathrm{T}$-cell responses in vivo}

Next we aimed at assessing the potency of $\mathrm{C} 5 \mathrm{aR}^{-1-}$ DCs to promote the expansion and the survival of allergen-specific $\mathrm{CD}^{+}{ }^{+} \mathrm{T}$ cells in vivo. For this purpose, we injected CFSElabeled OVA TCR-transgenic CD4 ${ }^{+} \mathrm{T}$ cells from DO11.10 $\mathrm{RAG}^{-1-}$ mice intravenously into wt recipient mice. The next day, we transferred DQ-OVA-pulsed wt or C5aR ${ }^{-1-}$ DC IT into wt mice. Five or nine days later, we assessed the proliferation and the frequency of OVA-specific $\mathrm{T}$ cells in the lung and in pulmonary lymph nodes (Figure 6a). On days 5 and 9 , the frequencies of DO11.10 $\mathrm{TCR}^{+} \mathrm{T}$ cells in the lymph nodes did not differ between the two treatment groups (Figure 6b,c). However, we noticed slightly decreased T-cell proliferation in the lymph nodes after adoptive transfer of C5 $\mathrm{aR}^{-1-}$ DCs (Figure 6b). In the lung, the CFSE signal on days 5 and 9 were too low to assess any differences in T-cell proliferation (data not shown), suggesting that the OVAspecific $\mathrm{T}$ cells that we detected in the lung were highly proliferated effector $\mathrm{T}$ cells that had migrated from the pulmonary lymph nodes into the lung. On day 5, we already found a slightly decreased frequency of DO11.10 $\mathrm{TCR}^{+} \mathrm{T}$ cells in the lung of wt mice adoptively transferred with $\mathrm{C} \mathrm{aR}^{-1-}$ DCs. On day 9 , the frequency of DO11.10 $\mathrm{TCR}^{+} \mathrm{T}$ cells in the lung was reduced by $70 \%$ in wt mice that had received $\mathrm{C}_{\mathrm{a}} \mathrm{R}^{-1-}$ DCs as compared with mice adoptively transferred with wt DCs (Figure 6d,e). These data are in line with our in vitro findings of increased T-cell apoptosis after stimulation with $\mathrm{C}_{\mathrm{a}} \mathrm{aR}^{-1-}$ DCs. Together, our findings

\footnotetext{
Figure 3 The DQ-OVA ${ }^{\text {lo }}$ dendritic cells (DCs) induce the asthmatic phenotype after adoptive transfer. (a) Experimental design. Briefly, GM-CSF (granulocyte macrophages colony-stimulating factor)-differentiated bone marrow (BM) cells were pulsed overnight with $1 \mu \mathrm{m}$ DQ-OVA. The next day, $D Q-O V A^{\text {hi }}$ cells were separated from DQ-OVA ${ }^{l o}$ cells by fluorescence-activated cell sorting before adoptive transfer. One million DQ-OVA ${ }^{\text {hi }}$ or DQ-OVA ${ }^{\text {lo }}$ DCs were given intratracheally (IT) into BALB/c wild-type (wt) recipients. After 10 days, recipient mice were challenged IT with ovalbumin (OVA). Seventy-two hours after the injection, airway responsiveness was determined. Subsequently bronchoalveolar lavage (BAL) fluid, lung cells, and tissues were collected for further analysis. (b) Airway hyperresponsiveness (AHR) in response to IT administration of metacholine measured as airway resistance using Flexivent. (c) Total and differential cell counts in BAL fluid. (d) Histological examination of airway inflammation. Sections were stained with hematoxylin and eosin (original magnification $\times 200$ ). (e) Histological examination of goblet cell hyperplasia. Sections were stained with periodic acid-Schiff for mucus production (original magnification $\times 200$ ). Mucus producing airways are plotted relative to all analyzed airways (right panel). (f) Cytokine profile of pulmonary cells harvested from mice $72 \mathrm{~h}$ after OVA challenge. Supernatants were collected $72 \mathrm{~h}$ after in vitro cell culture. Values shown are the mean $\pm \mathrm{s}$.e.m.; $n=9-10 \mathrm{per}$ group, ${ }^{\star} P<0.05$, ${ }^{\star \star} P<0.01,{ }^{* \star *} P<0.001$. IFN, interferon; IL, interleukin; Th, T helper; TNF, tumor-necrosis factor.
} 
a
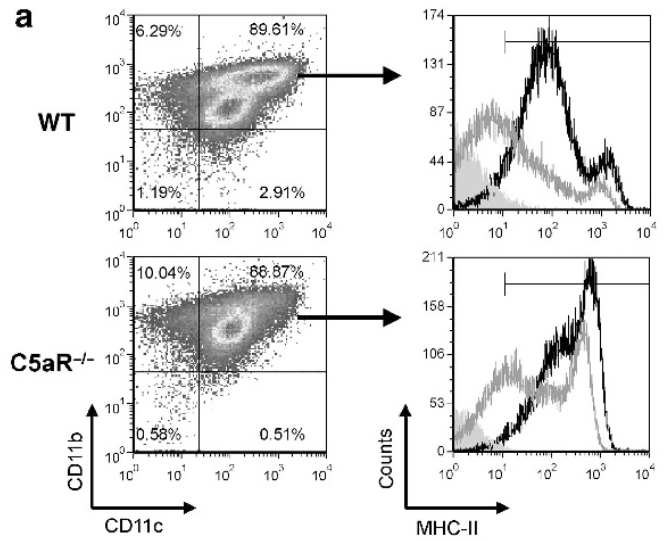
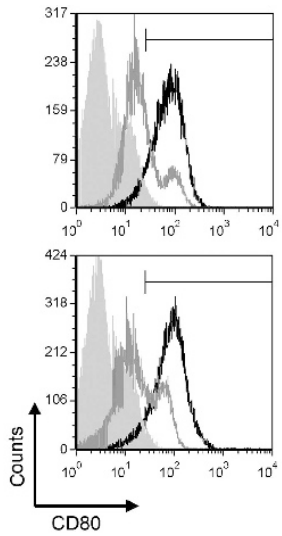
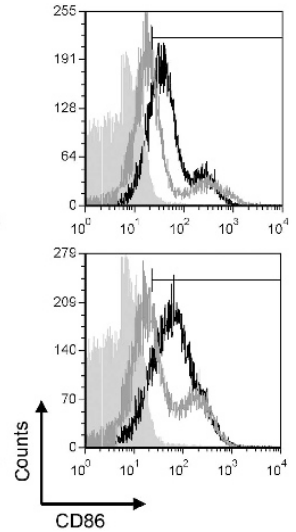
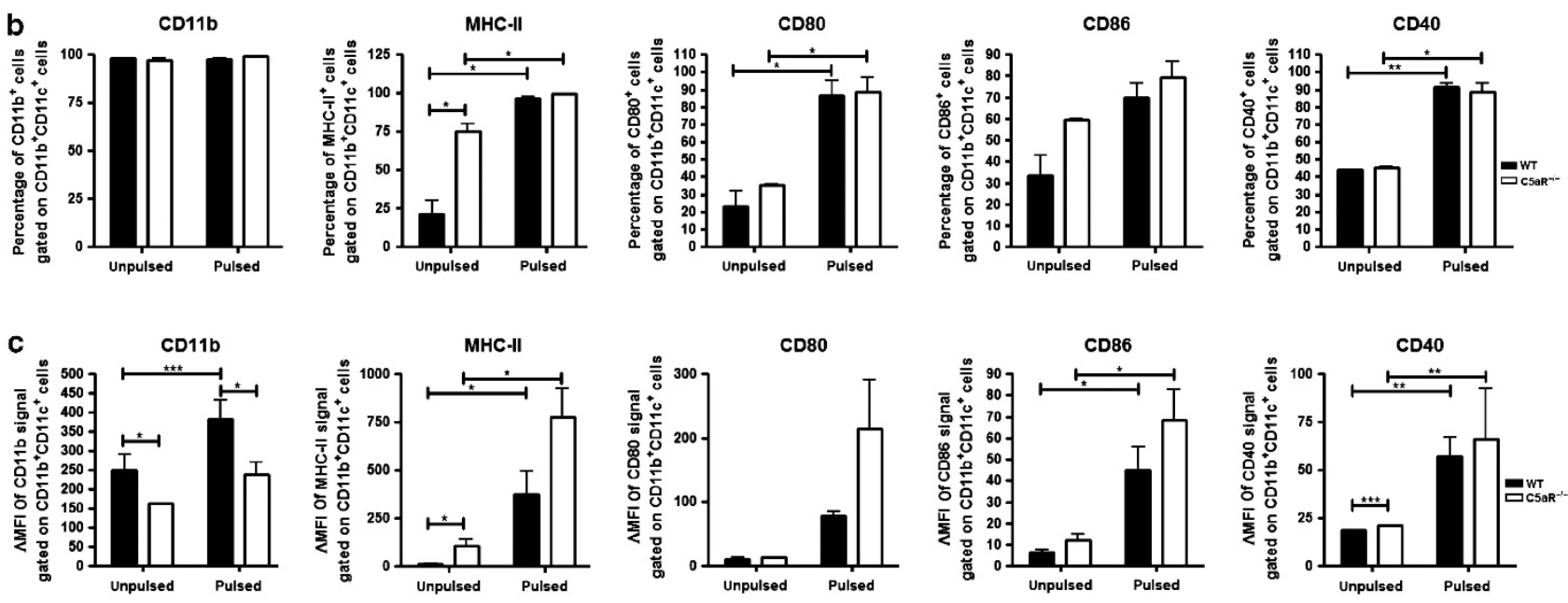

d
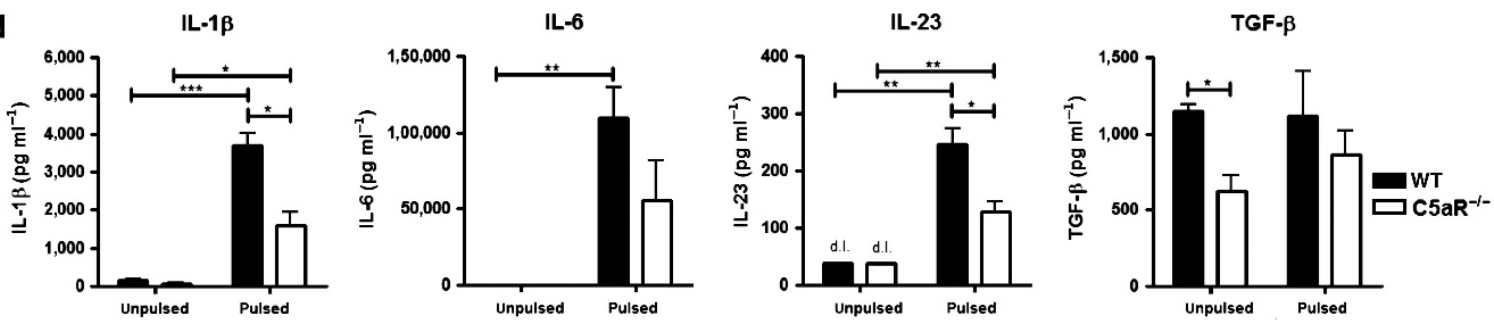

IL-12p40

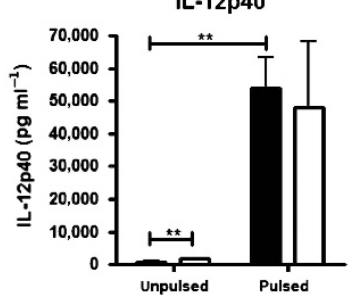

IL-12p70

IL-33
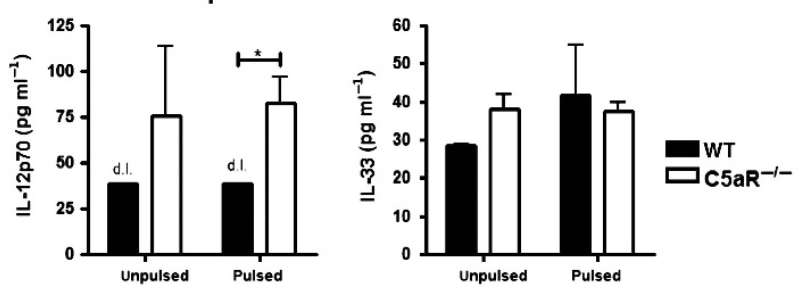

Figure $4 \mathrm{C} \mathrm{aR}^{-1-}$ dendritic cells (DCs) show a regular maturation profile but produce less Th17-promoting cytokines in vitro. (a) Expression profile of major histocompatibility complex II (MHC-II) and costimulatory molecules on wild-type (wt) and C5aR ${ }^{-1-}$ bone marrow (BM)-derived DCs

following stimulation with fluorescein isothiocyanate-ovalbumin (FITC-OVA) for $24 \mathrm{~h}$. Gray histograms depict the isotype control. The gray and the black lines represent the expression before and after OVA stimulation, respectively. Histograms are representative of three experiments. (b) Frequency of $\mathrm{CD}_{11 \mathrm{~b}}{ }^{+}, \mathrm{MHC}-\mathrm{II}^{+}, \mathrm{CD} 80^{+}, \mathrm{CD}_{6}{ }^{+}$, or $\mathrm{CD} 40^{+} \mathrm{DCs}$ in $\mathrm{BM}$ cultures from wt and C5aR ${ }^{-1-}$ mice. (c) Relative expression of CD11b, MHC-II, CD80, CD86, or CD40 as compared with isotype control staining ( $\mathrm{MFI}$ (mean fluorescent intensity)). (d) Cytokine profiles from BM-derived DCs after OVA stimulation for $24 \mathrm{~h}$. Values shown are the mean \pm s.e.m.; $n=3-6$ per group, d.I. indicates that the mean is below detection limit, ${ }^{\star} P<0.05$, ${ }^{\star *} P<0.01,{ }^{* * *} P<0.001$. IL, interleukin; TGF, transforming growth factor.

suggest that $\mathrm{C} 5 \mathrm{aR}^{-1-} \mathrm{DCs}$ promote $\mathrm{T}$-cell proliferation in the pulmonary lymph with a similar potency as wt DCs. However, once activated, OVA-specific effector T cells that have migrated back into the lung suffer from accelerated cell death, resulting in a decreased frequency of OVA-specific T cells after primary antigen encounter. 
Increased frequency of myeloid-derived suppressor cells in BMDC preparations from C5aR-deficient mice

MDSC are a heterogeneous population of myeloid progenitor cells and immature myeloid cells that reside in the BM and with low frequency in the spleen. ${ }^{24}$ They express the CD11b and $\mathrm{Gr}-1$ markers and can be further divided into $\mathrm{CD} 11 \mathrm{~b}^{+} \mathrm{Ly}_{6 \mathrm{C}}{ }^{+}$ Ly6G $^{-}$monocytic MDSCs (M-MDSC) and CD11b ${ }^{+}$Ly6C $^{-}$ Ly6G ${ }^{+}$granulocytic MDSCs (G-MDSC). ${ }^{25}$ They are potent suppressors of T-cell functions. Recent reports provide evidence that MDSCs can be induced in BM cultures by IL- $6^{26}$ or lipopolysaccharide ${ }^{27,28}$ treatment in vitro and in murine airways ${ }^{28}$ and can suppress Th2 effector functions. Intense cross-talk between TLR and C5aR signaling has been shown previously. ${ }^{15,29,30}$ Further, during GM-CSF differentiation, BM cells locally produce $\mathrm{C} 5$ and $\mathrm{C} 5 \mathrm{a}^{21}$ Based on these findings and our data that $\mathrm{C} 5 \mathrm{aR}^{-1-}$ BMDCs differ in antigen uptake and processing, CD11b and MHC-II expression as well as in their cytokine profile, we hypothesized that $\mathrm{C} 5 \mathrm{aR}$ deficiency during DC differentiation may also affect the differentiation of MDSCs. As shown in Figure 7a (left panel), the majority of wt and $\mathrm{C} 5 \mathrm{aR}^{-1-} \mathrm{BM}$ cells were $\mathrm{CD} 11 \mathrm{~b}^{+} \mathrm{CD} 11 \mathrm{c}^{+}$DCs that were negative for the Gr-1 and the F4/80 markers. However, we found a discrete population of $\mathrm{CD} 11 \mathrm{~b}{ }^{\text {hi }} \mathrm{CD} 11 \mathrm{c}^{\text {int }} \mathrm{Gr}-1^{+} \mathrm{F} 4 / 80^{+}$cells in wt BM cultures, the frequency of which was 2.5-fold higher in $\mathrm{C} 5 \mathrm{aR}^{-/-} \mathrm{BM}$ cultures (Figure 7a, middle panel). Administration of $50 \mathrm{~nm}$ C5a to wt cultures during differentiation had no additional suppressive effect on the frequency of $\mathrm{CD} 11 \mathrm{~b}^{\text {hi }} \mathrm{CD} 11 \mathrm{c}^{\text {int }}$ $\mathrm{Gr}-1^{+} \mathrm{F} 4 / 80^{+}$cells (data not shown), suggesting that the endogenous $\mathrm{C} 5 \mathrm{a}$ is sufficient to control the expansion of the $\mathrm{CD} 11 \mathrm{~b}^{\text {hi }} \mathrm{CD} 11 \mathrm{c}^{\text {int }} \mathrm{Gr}-1^{+} \mathrm{F} 4 / 80^{+}$cells. When we sorted such cells from $\mathrm{C} 5 \mathrm{aR}^{-1-}$ mice, most of them had a monocytoid morphology (Figure $7 \mathbf{b}$ ). In addition to their surface marker expression, MDSCs can be functionally characterized by the production of free radicals, which depends on the expression of arginase 1 and NOS2 among other mechanisms. ${ }^{24}$ We found that $\mathrm{CD} 11 \mathrm{~b}^{\text {hi }} \mathrm{CD} 11 \mathrm{c}^{\text {int }} \mathrm{Gr}$ $1^{+} \mathrm{F} 4 / 80^{+}$cells from $\mathrm{C} 5 \mathrm{aR}^{-/}$mice express higher mRNA levels of NOS2 under steady state conditions than cells from wt mice. Stimulation of such cells with IL-4 resulted in a fivefold (wt mice) or 2.5-fold ( $\mathrm{C} 5 \mathrm{aR}^{-1-}$ mice) increase of arginase mRNA as compared with steady state conditions, whereas NOS2 decreased significantly in suppressor cells from wt and $\mathrm{C}_{\mathrm{a}} \mathrm{aR}^{-1-}$ mice (Figure 7c). Taken together, we found a higher frequency of $\mathrm{CD} 11 \mathrm{~b}^{\text {hi }} \mathrm{CD} 11 \mathrm{c}^{\text {int }} \mathrm{Gr}-1^{+} \mathrm{F} 4 / 80^{+} \mathrm{SC}$ in $\mathrm{BM}$ cultures from $\mathrm{C} 5 \mathrm{aR}^{-1-}$ mice as compared with wt mice. Such cells phenotypically resemble M-MDSC and produce arginase and NOS2, which have been shown to contribute to the T-cell suppressive functions of MDSCs. ${ }^{24}$

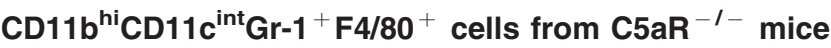 suppress Th2 responses in vivo}

To determine the functional relevance of the $\mathrm{C} 5 \mathrm{aR}^{-1-} \mathrm{SC}$ for BMDC-mediated induction of experimental allergic asthma, we complemented $1 \times 10^{6}$ wt BMDCs with $3 \times 10^{4}$ $\mathrm{CD}_{11} \mathrm{~b}^{\text {hi }} \mathrm{CD} 11 \mathrm{c}^{\text {int }} \mathrm{Gr}-1^{+} \mathrm{F} 4 / 80^{+}$SC from GM-CSF- differentiated BM cultures of $\mathrm{C} 5 \mathrm{aR}^{-1-}$ mice (Figure 8a). After stimulation with phosphate-buffered saline or DQ-OVA, the cell mixture was administered IT into $\mathrm{BALB} / \mathrm{c}$ wt mice, which were re-challenged with OVA 10 days later. Addition of $\mathrm{C}_{5} \mathrm{aR}^{-1-} \mathrm{SC}$ had no impact on airway resistance (Figure $\mathbf{8 b}$ ). By contrast, the eosinophilic and neutrophilic pulmonary infiltration observed with OVA-pulsed wt BMDCs was markedly reduced in the presence of $\mathrm{C}_{5} \mathrm{aR}^{-/-} \mathrm{SCs}$ (Figure 8c,d). By contrast, goblet cell hyperplasia and mucus production were comparable in the two groups (Figure 8e). IL-4, IL-5, and IL-10 levels were markedly reduced in the presence of $\mathrm{C}_{5} \mathrm{aR}^{-1-}$ SCs (Figure 8f). The reduced IL-5 levels fit well with the decreased eosinophilic airway inflammation, as IL-5 is critical for the mobilization of eosinophils from the BM. By contrast, addition of $\mathrm{C} 5 \mathrm{aR}^{-/}-\mathrm{SC}$ had no impact on IL-13 production (Figure 8f), which is in line with our data that the $\mathrm{C} 5 \mathrm{aR}^{-1-} \mathrm{SC}$ treatment group showed no change in AHR (Figure $8 \mathbf{b}$ ) and mucus production (Figure 8e). Finally, we found no impact of $\mathrm{C} 5 \mathrm{aR}^{-/-} \mathrm{SC}$ on TNF- $\alpha$, IL-17, and IFN- $\gamma$ production (Figure $8 \mathbf{f}$ ). The high IL-17 levels in the $\mathrm{C} 5 \mathrm{aR}^{-/}-\mathrm{SC}$ treatment group are surprising, as we found a substantial decrease in neutrophil numbers in this group as compared with the untreated control group. Recent reports suggest that IL-17 and TNF- $\alpha$ are critical factors for airway neutrophilia. ${ }^{31,32}$

\section{$\mathrm{CD}_{11 b^{\text {hi }}} \mathrm{CD} 11 \mathrm{c}^{\mathrm{int}} \mathrm{Gr}-1^{+} \mathrm{F} 4 / 80^{+}$cells from wt ${ }^{-}$mice suppress Th2, Th17 and Th1 responses in vivo}

To determine potential qualitative and quantitative differences between $\mathrm{C}_{5} \mathrm{aR}^{-1-}$ and wt SC, we mixed $1 \times 10^{6}$ wt BMDCs with $3 \times 10^{4} \quad \mathrm{CD} 11 \mathrm{~b}^{\text {hi }} \mathrm{CD} 11 \mathrm{c}^{\text {int }} \mathrm{Gr}-1^{+} \mathrm{F} 4 / 80^{+}$SC from GM-CSF-differentiated BM cultures of wt mice (Figure 9a). After stimulation with phosphate-buffered saline or DQ-OVA, the cell mixture was administered IT into BALB/c wt mice, which were re-challenged with OVA 10 days later. Addition of wt SCs strongly reduced airway resistance (Figure 9b). Further, eosinophilic and neutrophilic airway inflammation observed with OVA-pulsed wt BMDCs was markedly reduced in the presence of wt SCs (Figure 9c,d). However, total cells and lymphocyte numbers were not affected. Also, goblet cell hyperplasia and mucus production were similar between the two groups (Figure 9e). IL-4, IL-5, and IL-13 levels were markedly reduced in the presence of wt SCs, whereas we found only a trend for the reduction of IL-10 (Figure 9f). The decreased IL-13 levels fit well with the decreased airway resistance. Finally, TNF- $\alpha$ levels increased, whereas IL-17A decreased, although this drop in IL-17A did not reach the level of statistical significance (Figure 9f).

\section{DISCUSSION}

C5a exerts a dual role in allergic asthma. During the effector phase, it drives the allergic inflammation, ${ }^{6,12,13}$ whereas it protects from the development of maladaptive Th2 immune responses during allergen priming. ${ }^{6,14}$ Given that DCs are of major importance for allergen sensitization, we hypothesized that C5a may suppress DC activation at allergen encounter. 
a
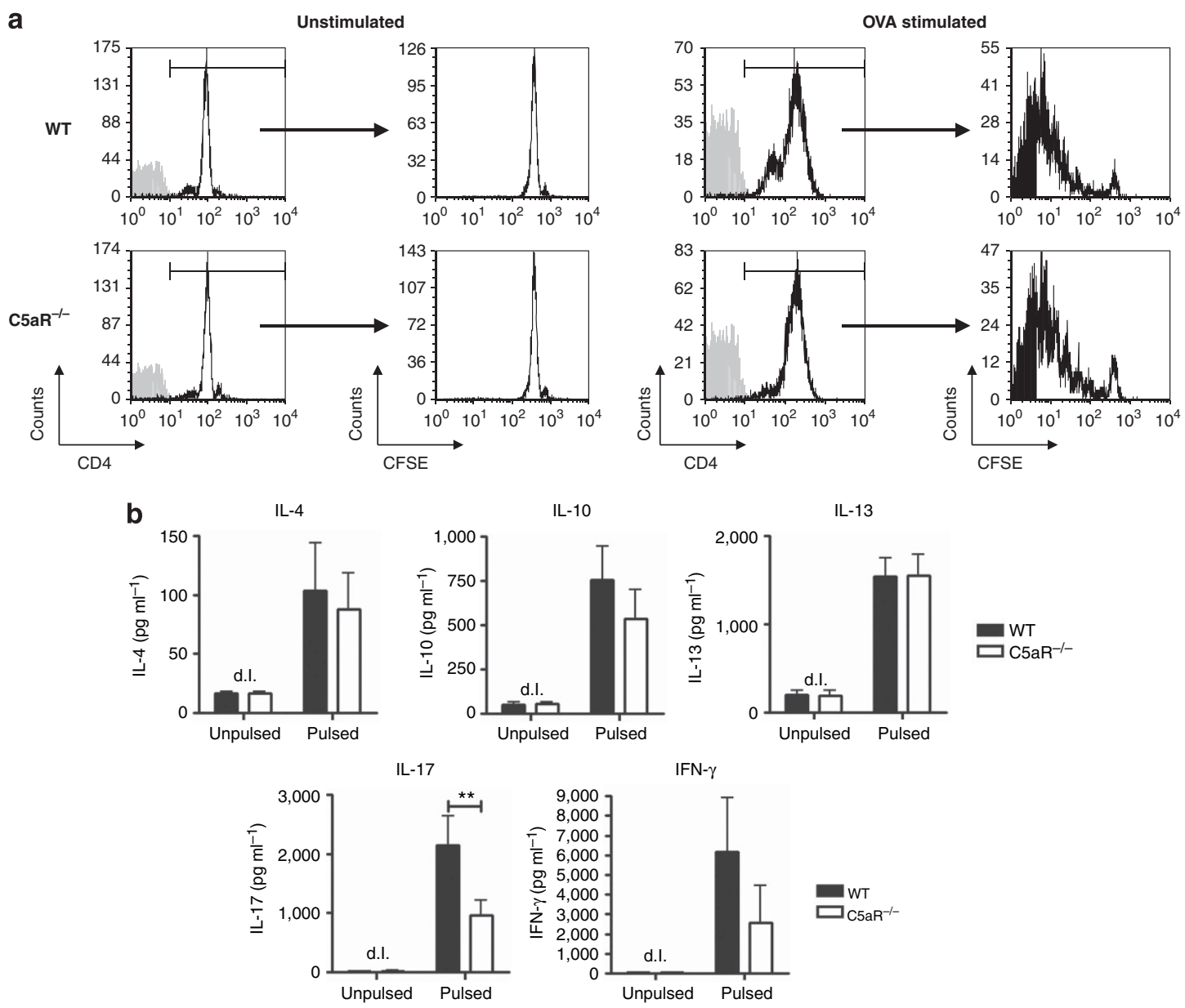

c
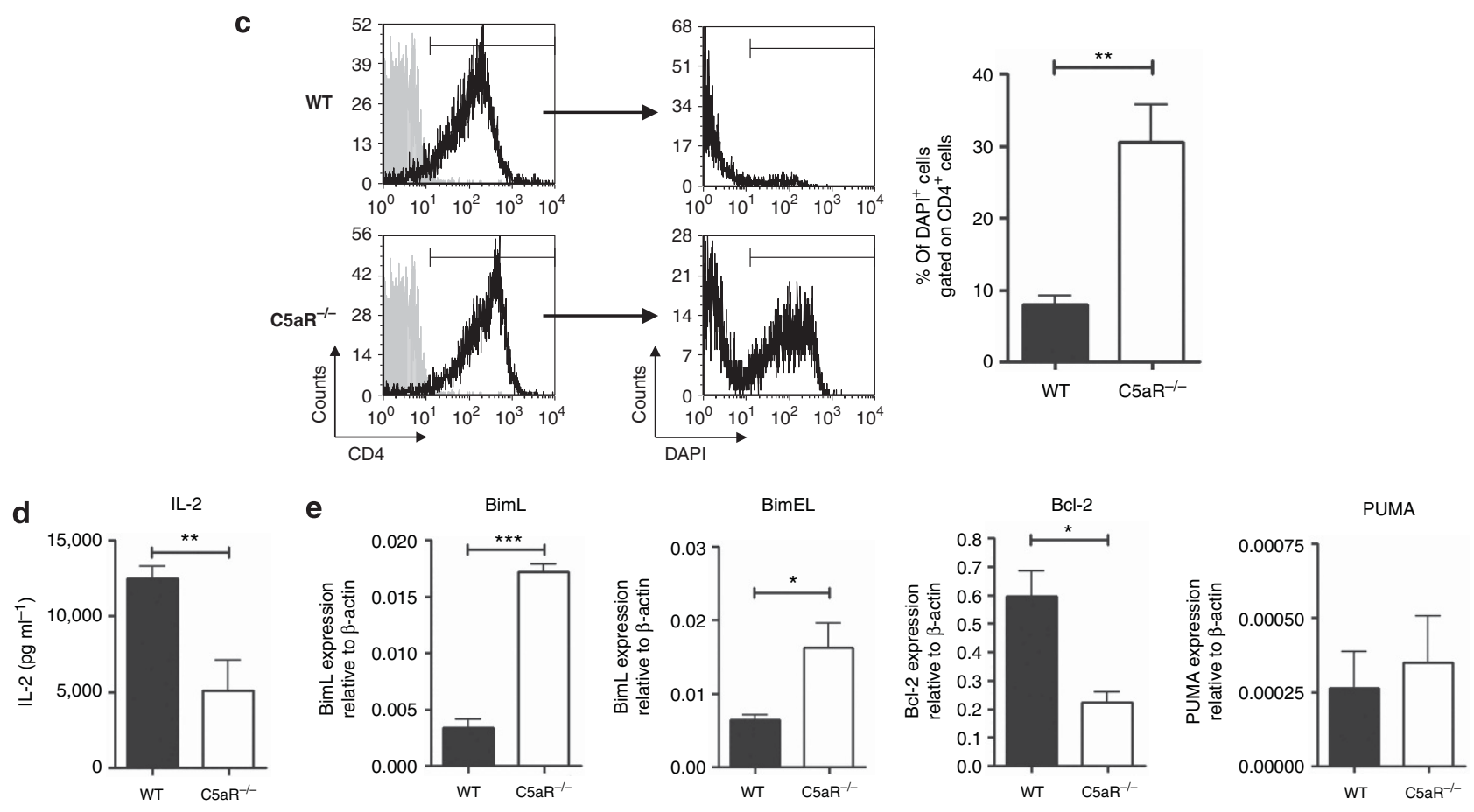
To test this hypothesis, we focused on GM-CSF-differentiated BMDCs that have been widely used in adoptive transfer studies as they promote the development of maladaptive Th2 and Th17 responses in the lung. ${ }^{17,19,33}$ BMDCs express the CD11c, $\mathrm{CD} 11 \mathrm{~b}, \mathrm{CD} 47$, and signal regulatory protein (SIRP)- $\alpha$ markers but not CD103, suggesting that they functionally resemble

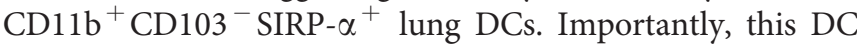
population can drive Th2 responses in mediastinal lymph nodes and in the lung. ${ }^{2,3}$ We found a mixed eosinophilic and neutrophilic airway inflammation that was associated with AHR and Th2, Th17, and Th1 cytokine production. Surprisingly, the allergic phenotype was markedly reduced after adoptive transfer of C5aR-deficient cDCs. $\mathrm{C}_{5} \mathrm{aR}^{-1-}$ DCs failed to promote significant allergen-specific Th2 cytokine production, resulting in decreased AHR and minor allergenspecific mucus production. This is in sharp contrast to our previous findings and suggests that in vivo $\mathrm{C} 5 \mathrm{aR}$-activation on other cell types besides DCs such as tissue resident alveolar macrophages or airway epithelial cells has to be considered, both of which express $\mathrm{C} 5 \mathrm{aR}^{34,35}$ and exert immunoregulatory properties. Indeed, airway epithelial cells secrete several cytokines, including GM-CSF, TSLP, IL-25, IL-33, and IL-1 family members, upon allergen contact that promote DC maturation enabling them to differentiate naive $\mathrm{T}$ cells into $\mathrm{Th} 2$ effector cells. ${ }^{1}$ In addition to C5aR, C5a can also interact with a second receptor, C5L2, which controls the development of Th1 and Th17 cells in experimental allergic asthma at the DC/T cell interface and promotes Th2 immune responses independent of pulmonary DCs. ${ }^{36}$ This effect may become dominant in vivo in the absence of C5aR. Finally, C5aR signaling in BMDCs may inappropriately reflect $\mathrm{C} 5 \mathrm{aR}$-mediated regulation of the distinct pulmonary DC subsets in vivo. In fact, C5aR targeting regulates the frequency of pulmonary pDCs expressing the costimulatory molecules $\mathrm{B} 7-\mathrm{H} 1$ and $\mathrm{B} 7-\mathrm{DC}$, which is critical for Th2 cytokine production from $\mathrm{CD} 4{ }^{+} \mathrm{T}$ cells. ${ }^{14}$

After adoptive transfer of $\mathrm{C} 5 \mathrm{aR}^{-1-}$ BMDCs, the airway inflammation was not only lower but was dominated by neutrophils. Eosinophilic airway inflammation is mainly driven by IL-5, whereas TNF- $\alpha$ and IL-17A synergize to recruit neutrophils into the airways. ${ }^{32}$ In line with this view, $\mathrm{C} 5 \mathrm{aR}^{-1-}$ DCs promoted allergen-specific production of TNF- $\alpha$ and IL-17A, although the IL-17A levels were lower as compared with the levels produced by wt DCs. Our in vitro data suggest that the decreased Th17-cell development results from a deficit of $\mathrm{C}_{\mathrm{a}} \mathrm{R}^{-1-}$ DCs to produce IL-1 $\beta$, IL-6, and IL-23. Such cytokines either promote Th17-cell differentiation or serve as growth factors for Th17 cells. ${ }^{37}$ In support of this view, we found decreased IL-17A production in co-cultures of $\mathrm{C}_{5} \mathrm{aR}^{-1-}$ DCs with OVA transgenic $\mathrm{CD}^{+} \mathrm{T}$ cells when compared with wt DC cultures. Together, our findings support a model in which the $\mathrm{C} 5 \mathrm{a}-\mathrm{C} 5 \mathrm{aR}$ axis is required for BMDCdriven Th17-cell differentiation. In contrast to our findings, Lajoie et al. ${ }^{9}$ recently reported that C5aR-deficient BMDCs produce more IL-23 than wt DCs, which was associated with strong Th17 immune responses in a HDM-model of pulmonary allergy. Further, C5aR deficiency did not affect DC-driven IL- 6 and IL- $1 \beta$ production in their study. The fact that HDM extract has been used to activate BMDCs may explain the opposing results. In line with the HDM study, spleen-derived C5 $\mathrm{aR}^{-1-}$ DCs, which were stimulated with a TLR2 ligand, produce more IL-23 and promote Th17-cell differentiation. ${ }^{15}$ However, similar to our data, Strainic et al. ${ }^{20}$ found reduced IL-23p19 mRNA levels in $\mathrm{OVA}_{323-330}$ peptide-stimulated BMDC/OT-II T-cell co-cultures, when the C5aR and the C3aR were pharmacologically targeted. Together, these findings suggest a complex regulatory role for the $\mathrm{C} 5 \mathrm{a}-\mathrm{C} 5 \mathrm{aR}$ axis in Th17 differentiation that depends on the nature of the antigen (HDM vs. OVA) and the subset of DCs that is activated (BMDCs vs. spleen DCs). The importance of the antigenpresenting cell type is further stressed by data obtained with mouse peritoneal macrophages and human monocytes. In this setting, C5a drives Th17-cell differentiation by a strictly IL-6dependent mechanism. ${ }^{30,38,39}$ In future studies, it will be important to delineate the signaling pathways activated by the complex allergens like HDM and the cross talk between C5aR, C5L2, and TLRs in the context of C5aR and C5L2 deficiencies. As we and others have shown before, cross-regulation exists between the different anaphylatoxin receptors ${ }^{14,40}$ that can affect the signaling program in different DC subsets ultimately defining the production of cytokines that regulate the lineage commitment of naive Th cells.

The unexpected finding that the absence of the $\mathrm{C} 5 \mathrm{aR}$ in $\mathrm{BM}$ derived $\mathrm{CDC}$ results in decreased $\mathrm{Th} 2 \mathrm{immune}$ responses in vivo was associated with: (i) a functional defect of $\mathrm{C} 5 \mathrm{aR}^{-1-} \mathrm{DCs}$ to appropriately take up and process the model antigen OVA; and (ii) a higher frequency of more mature DCs expressing higher levels of MHC-II. It has been demonstrated that antigen uptake and processing correlates with the maturation status of DCs. ${ }^{41,42}$ Our data suggest that $\mathrm{C} 5 \mathrm{aR}$ activation during GM-CSF-mediated DC differentiation is an important signal that keeps DCs in a more immature state required for antigen sensing. We were not able to assign the decreased potency of antigen uptake to a particular endocytosis pathway. Scavenger receptor-mediated endocytosis and micropinocytosis were

\footnotetext{
Figure $5 \mathrm{C} \mathrm{aR}^{-1-}$ dendritic cell (DC)-activated CD4 ${ }^{+}$T cells produce less interleukin (IL)-17A and interferon (IFN)- $\gamma$ and suffer from accelerated cell death. (a) Spleen derived carboxyfluorescein diacetate succinimidyl ester (CFSE)-labeled CD4 ${ }^{+}$T cells from OVA-TCR (ovalbumin-T-cell receptor) transgenic DO11.10/Rag2 ${ }^{-l-}$ cells were co-cultured for 4 days in the presence of bone marrow (BM)-derived DCs with or without OVA (1 $\left.\mu \mathrm{M}\right)$. CFSE expression in $\mathrm{CD4}^{+}$cells was evaluated by flow cytometry. Histograms are representative of four independent experiments. (b) Cytokine

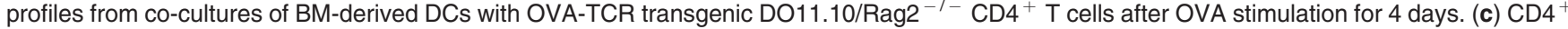
T-cell survival as assessed by 4',6-diamidino-2-phenylindole (DAPI) staining after 7 days of co-culture. Histograms are representative of five independent experiments. (d) Levels of IL-2 in supernatants collected after 7 days of co-culture. (e) Expression profile of pro- and anti-apoptotic molecules evaluated by real-time reverse transcriptase-PCR. Values shown are the mean \pm s.e.m.; $n=4$, d.I. indicates that the mean is below detection limit, ${ }^{\star} P<0.05,{ }^{\star \star} P<0.01,{ }^{\star \star *} P<0.001$. WT, wild type.
} 
both reduced in $\mathrm{C} 5 \mathrm{aR}^{-1-}$ BMDCs. In line with previous studies ${ }^{4,43}$ we found that cells with a lower antigen uptake were more potent inducers of Th2 cytokines. However, we did not observe a shift towards a more pronounced production of IFN- $\gamma$ or IL-17 as reported for $\mathrm{CD} 11 \mathrm{~b}^{+} \mathrm{CD} 103^{+}$lung DCs in the presence of high antigen concentration. ${ }^{4}$ Despite the decreased uptake of OVA, C5aR $\mathrm{aR}^{-1-}$ DCs were not impaired in their ability to promote allergen-specific expansion of $\mathrm{CD} 4{ }^{+}$ $\mathrm{T}$ cells in vitro and only slightly impaired in vivo. Further, in contrast to the impaired Th2 response in vivo, Th2 cytokine

a

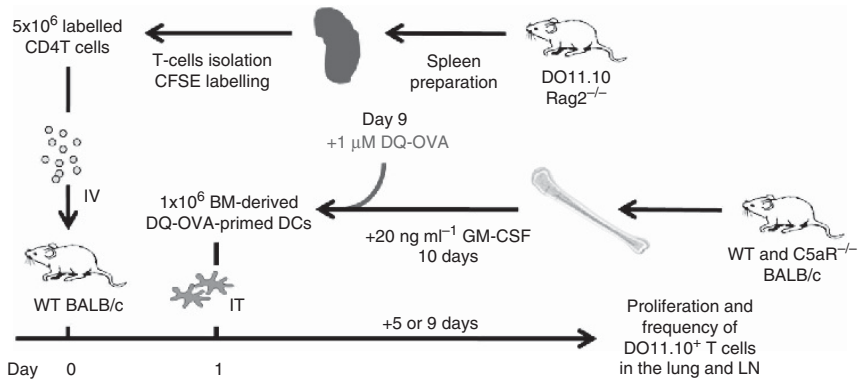

b
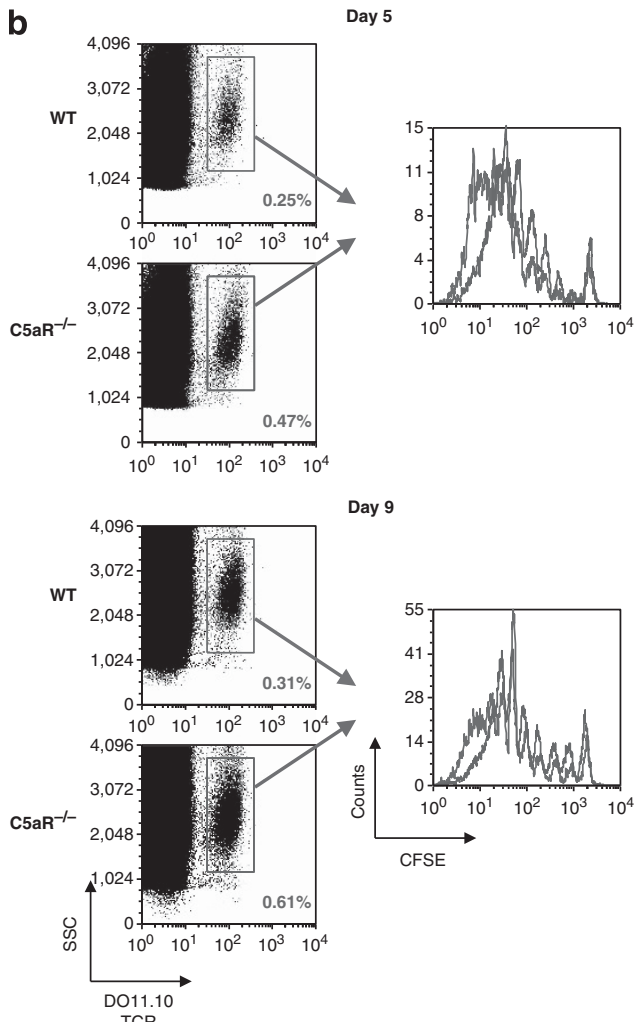

C
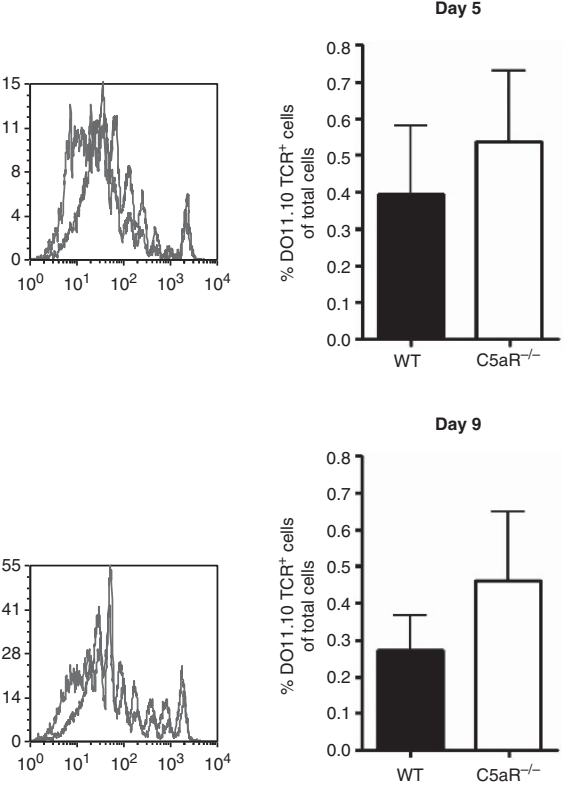

d
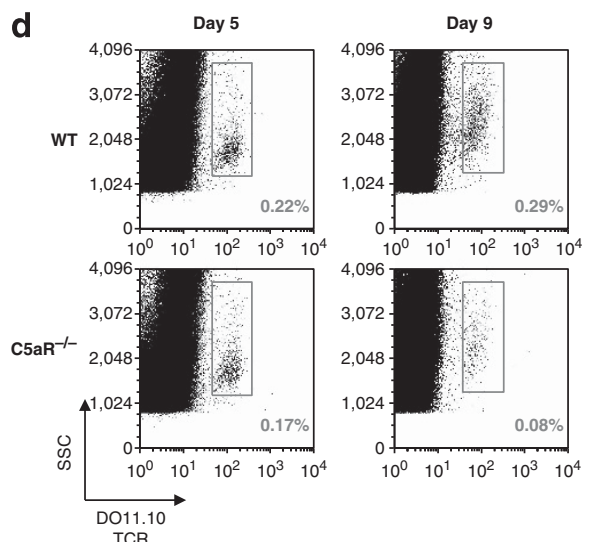

e
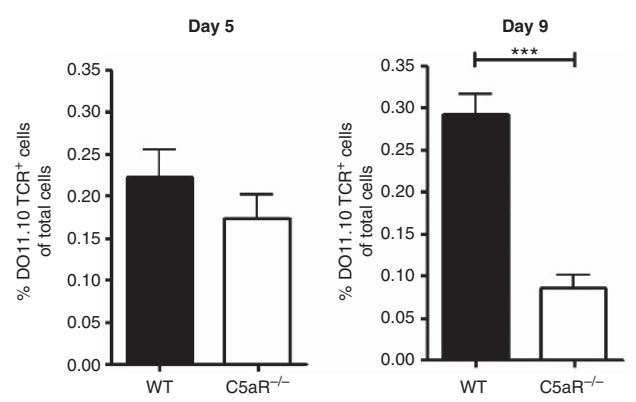
production from $\mathrm{CD}^{+}{ }^{+} \mathrm{T}$ cells in vitro was not affected. However, we observed an accelerated apoptosis rate of $\mathrm{C} 5 \mathrm{aR}^{-1-}$ DC-activated $\mathrm{CD}^{+} \mathrm{T}$ cells in vitro by activation of the intrinsic death pathway. Concomitant with a rapid decrease in IL-2, we found a substantial upregulation of the pro-apoptotic molecule Bim and a decrease of the pro-survival mediator Bcl-2. At this point, we do not know whether the faster contraction of activated CD4 ${ }^{+}$T cells results in lower frequency of memory T cells. However, it is tempting to speculate that the failure of $\mathrm{C} \mathrm{aR}^{-1-} \mathrm{cDCs}$ to mount a strong Th2 immune response

a
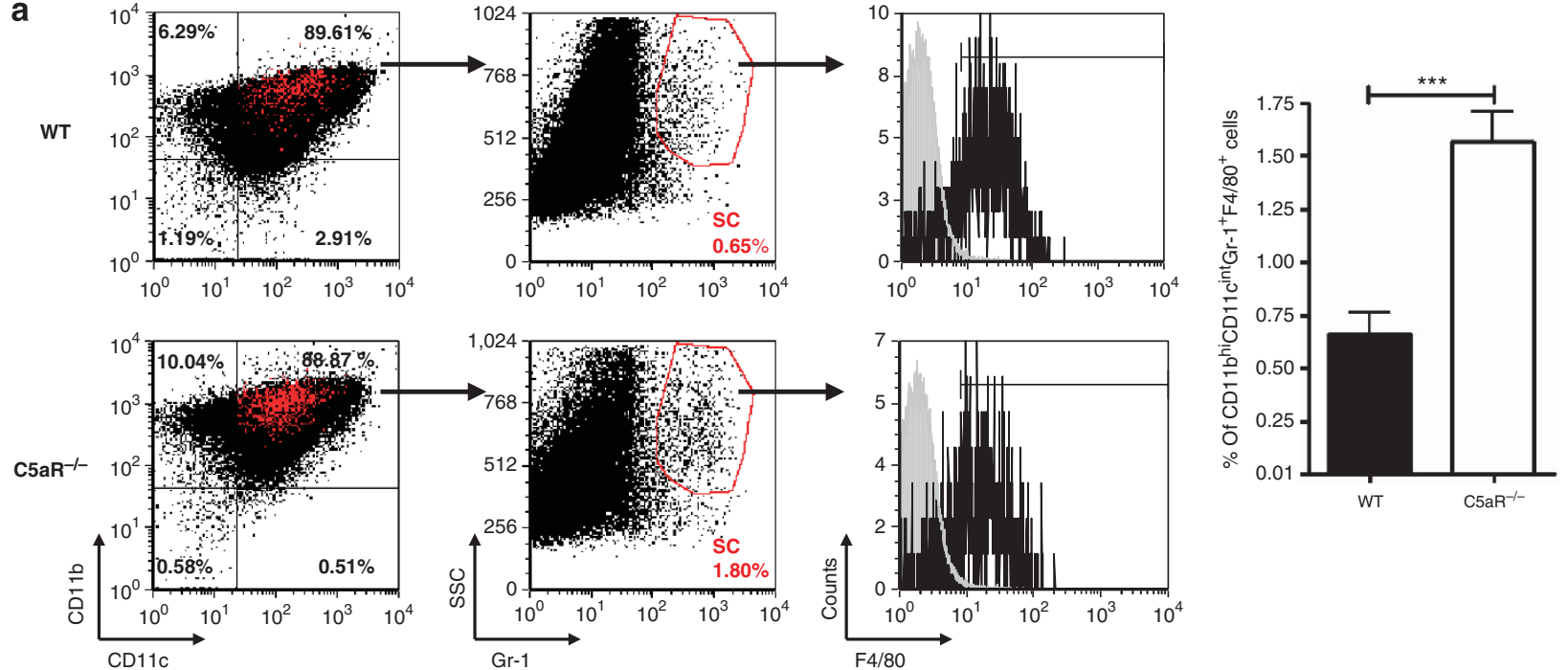

b
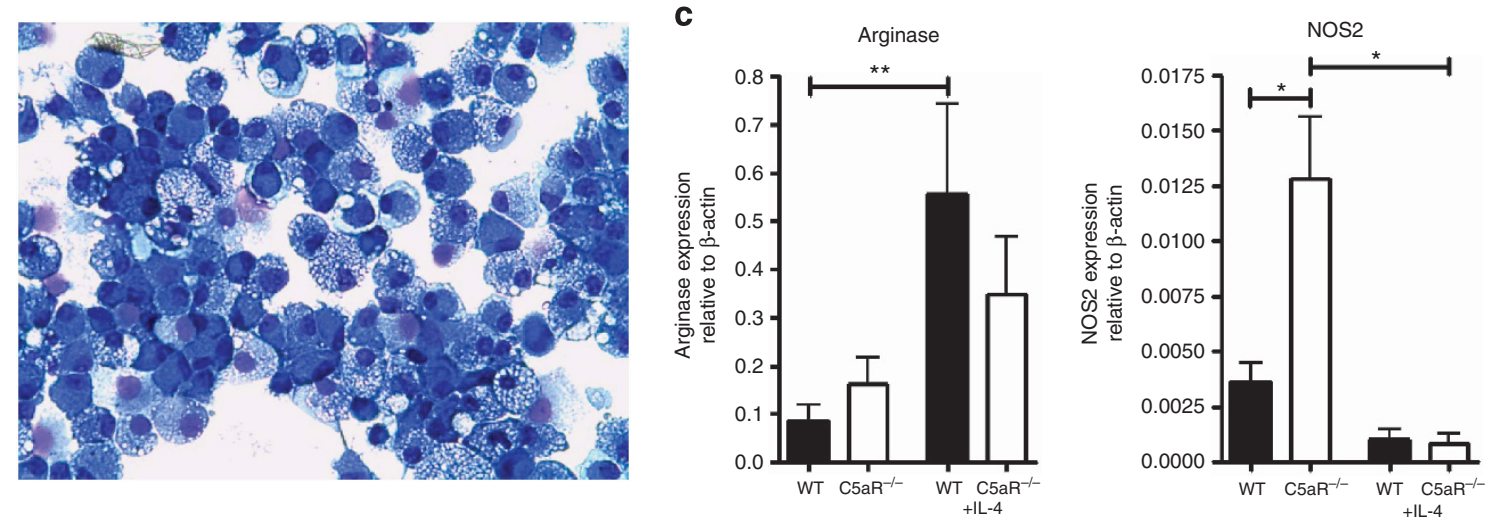

Figure 7 Bone marrow (BM) cultures from C5aR ${ }^{-1-}$ mice show an increased frequency of CD11 ${ }^{\text {hi }} \mathrm{CD} 11 \mathrm{c}^{\text {int }} \mathrm{Gr}-1^{+} \mathrm{F} 4 / 80^{+}$suppressor cells $(\mathrm{SC}$ ). (a) (first panel on the left) BM cells were first gated on $\mathrm{CD} 11 \mathrm{c}^{+} \mathrm{CD} 11 \mathrm{~b}^{+} \mathrm{cDC}$. Within this population, $\mathrm{SSC} \mathrm{C}^{\mathrm{hi}} \mathrm{Gr} 1^{+}{ }^{+}$cells were identified (second

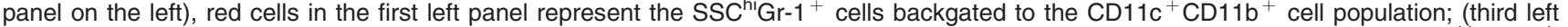
panel) histogram showing the F4/80 expression within the $\mathrm{CD} 11 \mathrm{~b}^{+} \mathrm{CD} 11 \mathrm{c}^{+} \mathrm{Gr}-1^{+}$cell population; (right panel) frequency of $\mathrm{CD} 11 \mathrm{~b}^{\text {hi }} \mathrm{CD} 11 \mathrm{c}^{\text {int }}$ $\mathrm{Gr}-1^{+} \mathrm{F} 4 / 80^{+}$cells in BM cultures from wild-type (wt) and C5aR ${ }^{-1-}$ mice. Data are representative of three independent experiments. (b) Morphology of purified C5aR ${ }^{-1-}$ SCs (May-Grünwald-Giemsa staining, original magnification $\times 400$ ). (c) Relative expression of arginase 1 and nitric oxide synthase 2 (NOS2) mRNA $\pm 50 \mathrm{ng} \mathrm{ml}^{-1}$ interleukin (IL)-4 from SCs as evaluated by real-time reverse transcriptase-PCR. Values shown are the mean \pm s.e.m.; $n \geqslant 3$ per group, ${ }^{*} P<0.05,{ }^{* \star} P<0.01,{ }^{* * *} P<0.001$

Figure 6 Bone marrow (BM)-derived dendritic cells (DCs) from C5aR ${ }^{-1-}$ mice induce decreased proliferation and survival of DO11.10 Rag2 ${ }^{-1-}$ T cells in vivo. (a) Experimental design. CD4 ${ }^{+}$T cells were purified from the spleens of DO11.10 Rag2 ${ }^{-1-}$ mice. In all, $5 \times 10^{6} \mathrm{~T}$ cells were labeled with carboxyfluorescein diacetate succinimidyl ester (CFSE) and intravenously (IV) injected into wild-type (wt) BALB/c recipient mice. Twenty-four hours later, mice were intratracheally treated with $10^{6} \mathrm{wt}_{\text {or }} \mathrm{C}_{\mathrm{aR}}{ }^{-1-}$ BMDCs pulsed with $1 \mu \mathrm{m}$ DQ-OVA (ovalbumin) for $24 \mathrm{~h}$. Five or nine days later, single-cell suspensions from the lungs and lymph nodes were prepared and the proliferation and the frequency DO11.10 $\mathrm{TCR}^{+}$(T-cell receptor) $\mathrm{T}$ cells was determined. (b) DO11.10 TCR ${ }^{+}$T cells in the lymph nodes on day 5 (first upper panel on the left) or day 9 (first lower panel on the left) after adoptive transfer of either wt or C5aR ${ }^{-1}$ BMDCs; overlay showing the CFSE signal within the DO11.10 TCR ${ }^{+}$T cells on day 5 (first upper panel on the right) or day 9 (first lower panel on the right) after adoptive transfer of wt (red) or C5aR ${ }^{-1-}$ (blue) BMDCs. Histograms are representative of $\geqslant 3$ independent experiments. (c) Frequency of DO11.10 TCR ${ }^{+}$T cells in the lymph node on day 5 (upper panel) or day 9 (lower panel) after adoptive transfer of wt or

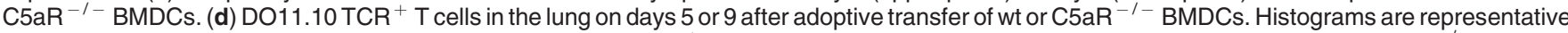
of $\geqslant 3$ independent experiments. (e) Frequency of D011.10 TCR ${ }^{+}$T cells in the lung on days 5 or 9 after adoptive transfer of wt or C5aR ${ }^{-1-}$ BMDCs. $^{-}$ Values shown are the mean \pm s.e.m.; $n \geqslant 3$ per group, ${ }^{* * *} P<0.001$. GM-CSF, granulocyte macrophages colony-stimulating factor; SSC, side scatter. The color reproduction of this figure is available on the Mucosal Immunology online. 
in vivo is due to a reduced number of Th2 memory cells. In support of this view, we observed a markedly reduced frequency of antigen-specific $\mathrm{CD} 4{ }^{+} \mathrm{T}$ effector cells that had homed to the lung 9 days after antigen-specific stimulation with OVA-pulsed BMDC from $\mathrm{C} 5 \mathrm{aR}^{-1-}$ mice. At this point, we cannot rule out that the decreased frequency of OVA-specific a

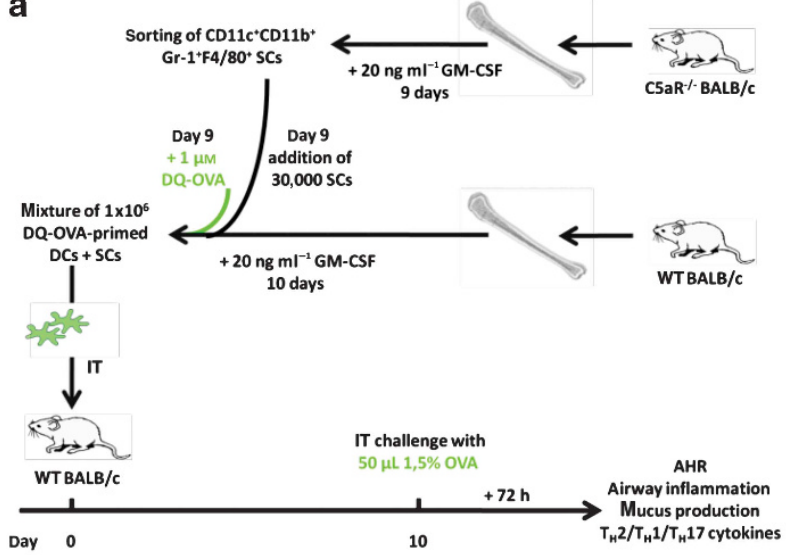

b

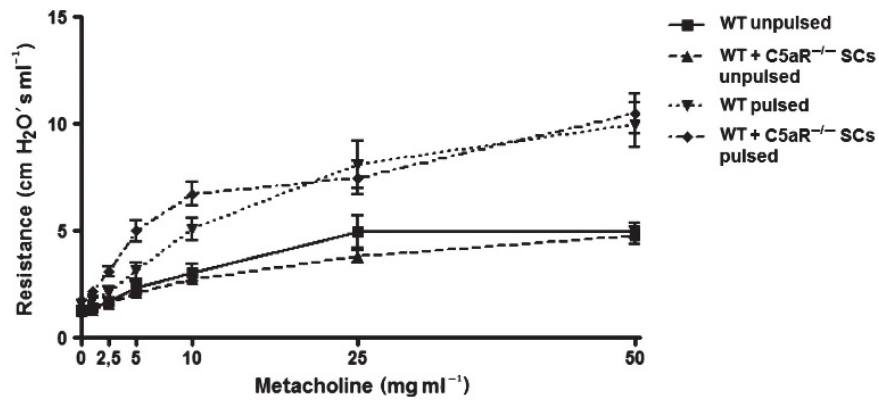

c
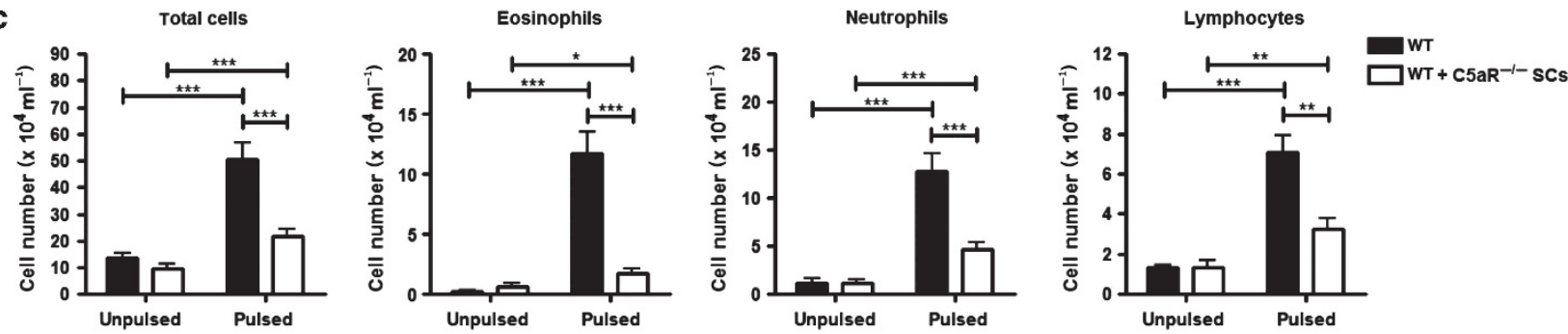

d

WT

$\mathrm{WT}+\mathrm{C} 5 \mathrm{aR} \mathrm{R}^{-1-} \mathrm{SCs}$
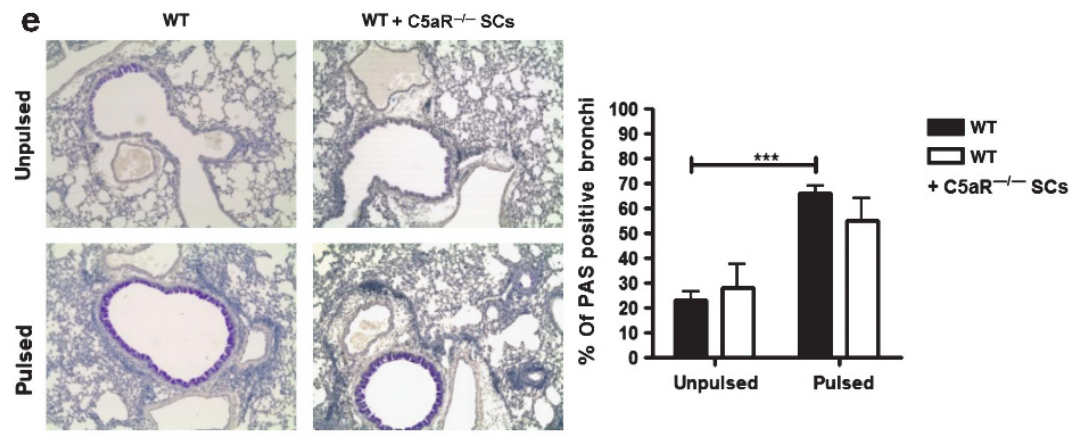

$\frac{.0}{5}$

कू
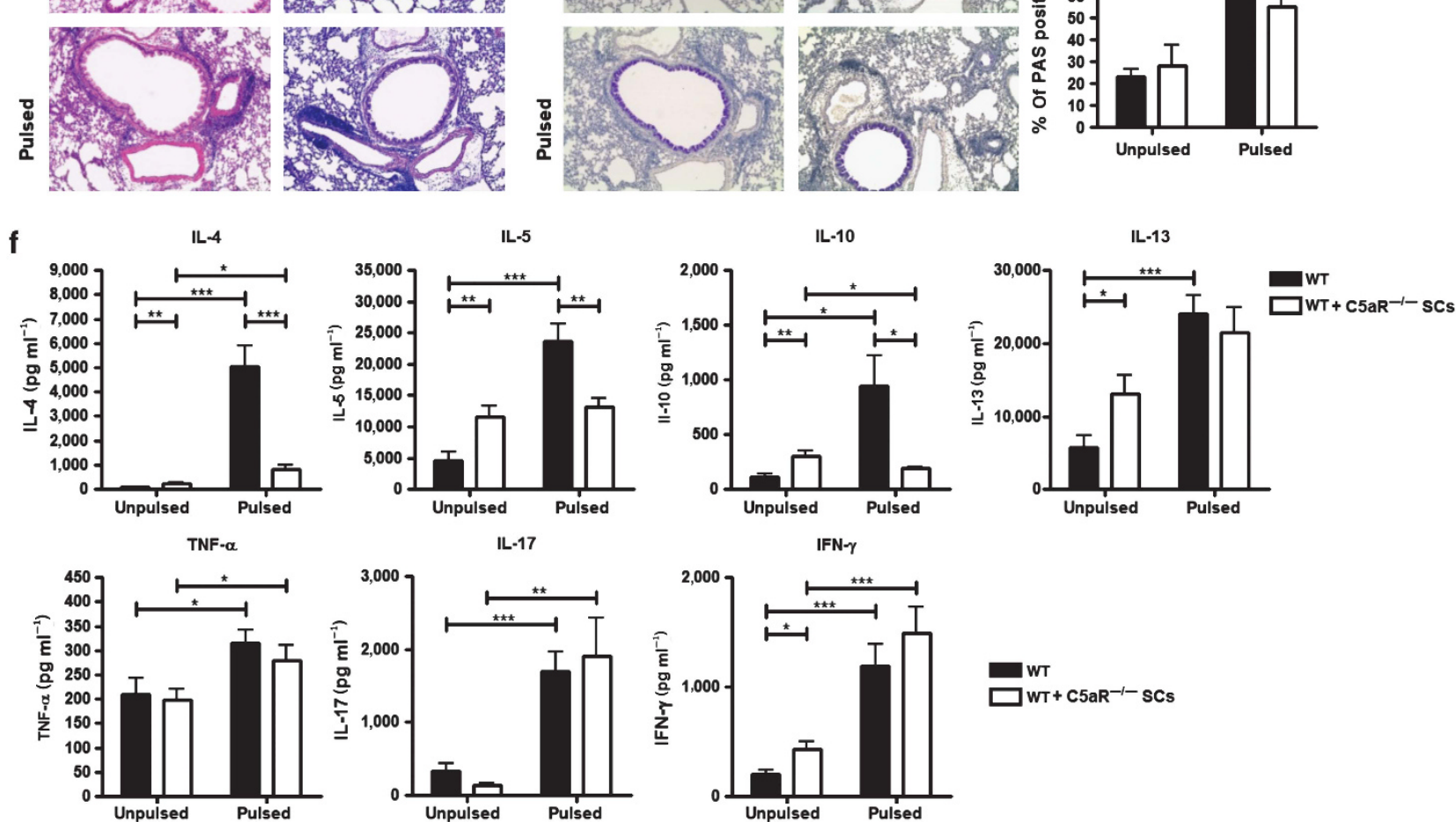

wT

$\square \mathrm{wT}+\mathrm{C} 5 \mathrm{aR}^{-1-\mathrm{SCs}}$ 
$\mathrm{T}$ cells in the lung results from decreased migration from the lymph nodes to the lung. However, as the frequency of OVAspecific $\mathrm{T}$ cells is only slightly reduced at day 5 , we consider it more likely that the reduced frequency of OVA-specific T cells on day 9 is due to an increased apoptosis rate of already migrated cells. An impact of C5aR signaling on T-cell viability has been demonstrated before, however, it has been mainly attributed to a lack of C5aR signaling in T cells. Strainic et al. ${ }^{20}$ described an autocrine feedback loop in $\mathrm{CD} 4{ }^{+} \mathrm{T}$ cells, in which $\mathrm{T}$ cells constitutively produce $\mathrm{C} 3 \mathrm{a}$ and $\mathrm{C} 5 \mathrm{a}$ that bind to their cognate anaphylatoxin receptors, thereby activating an AKTdependent signaling pathway preventing programmed cell death. Indeed, these authors found a decreased half-life of naive, unstimulated $\mathrm{T}$ cells. Further, the same authors found decreased levels of Bcl-2 but increased levels of caspase 3 and Fas in CD3/CD28-activated mouse $\mathrm{C}_{\mathrm{a}} \mathrm{R}^{-1-} \mathrm{T}$ cells. ${ }^{44} \mathrm{An}$ anti-apoptotic role for C5a has also been shown for human $\mathrm{T}$ cells. ${ }^{39}$ Together, the available data suggest a complex, antiapoptotic role for $\mathrm{C} 5 \mathrm{a}$ on $\mathrm{T}$ cells. Importantly, C5aR deficiency on T cells seems to affect steady state survival ${ }^{20}$ and early T-cell apoptosis during T-cell expansion, ${ }^{44}$ whereas C5aR deficiency in antigen-presenting cells, at least in BMDCs, promotes accelerated T-cell apoptosis during the contraction phase.

Another important finding of this study is the impact of $\mathrm{C} 5 \mathrm{aR}$ signaling on the development of a myeloid-derived suppressor population from BM cells. In BM cell cultures of C5aR-deficient mice, we found a 2.5 -fold increase in a $\mathrm{CD} 11 \mathrm{~b}^{\mathrm{hi}} \mathrm{CD} 11 \mathrm{c}^{\text {int }} \mathrm{Gr}-1^{+} \mathrm{F} 4 / 80^{+} \mathrm{SC}$ population as compared with $\mathrm{BM}$ cells from wt mice. This expansion of SCs in the absence of $\mathrm{C} 5 \mathrm{aR}$ appears to be independent of the SCpromoting cytokine IL-33, as we found very low levels of IL-33 in the BMDC cultures, which were not affected by the lack of C5aR. These cells phenotypically resembled M-MDSCs. ${ }^{25}$ MDSCs can be induced in vitro ${ }^{27}$ and in vivo in the lung by activation of the TLR4/MyD88 pathway and suppress allergen-induced airway inflammation. ${ }^{28}$ Further, distinct MDSC populations accumulate in the lung during experimental allergic asthma that either enhance or suppress T-cell responses. ${ }^{45} \mathrm{Wt}$ and C5aR SCs both expressed arginase- 1 and NOS2, the latter of which was significantly higher in C5aR SCs. The importance of NO for the T-cell suppressor activity of BMderived MDCS has been shown before. ${ }^{45,46}$ Interestingly, we found that in a Th2 environment, i.e., high IL-4, NOS2 expression is downregulated, whereas arginase 1 is upregulated.
These data may indicate that the local cytokine milieu defines the pathway by which SCs exert their immunoregulatory functions. Indeed, in a tumor model, C5a recruited highly suppressive G-MDSCs and increased the production of reactive oxygen and nitrogen species in M-MDSCs. ${ }^{47}$ In the OVA asthma model, we found a substantial decrease in the production of most Th2 cytokines and a marked reduction of the mixed eosinophilic/neutrophilic airway inflammation following adoptive transfer of a small number $\left(3 \times 10^{4}\right)$ of both wt and $\mathrm{C} 5 \mathrm{aR}^{-1-}$ SCs. An important quantitative difference between wt and $\mathrm{C} 5 \mathrm{aR}^{-1-}$ SCs is that the suppression of the airway inflammation is stronger after administration of $\mathrm{C} \mathrm{aR}^{-1-} \mathrm{SCs}$ as evidenced by the significant reduction of total cell and lymphocyte numbers and a stronger reduction of airway eosinophil and neutrophil numbers. These findings suggest that the decreased Th2 cytokine production and the low airway inflammation that we have observed in response to the adoptive transfer of BMDCs from $\mathrm{C}_{\mathrm{a}} \mathrm{aR}^{-1-}$ mice results from a suppressive effect of a small number of $\mathrm{C}_{5} \mathrm{aR}^{-1-}$ SCs that is present in the BM cell preparation. Wild-type (WT) and C5 $\mathrm{aR}^{-1-}$ SCs both reduced the production of IL-4, IL-5, and IL-10, although the magnitude of the reduction was higher when we used SCs cells from C5aR ${ }^{-1-}$ mice. Importantly, wt but not $\mathrm{C}_{5} \mathrm{aR}^{-1-} \mathrm{SCs}$ suppressed IL-13. In line with the failure of $\mathrm{C}^{2} \mathrm{aR}^{-1-}$ SCs to block IL-13, we observed no reduction in AHR and mucus production, both of which have been attributed to IL-13. ${ }^{48}$ Interestingly, the reduction of IL-13 levels by wt SCs resulted in reduced AHR but did not affect the mucus production. Given that IL-13 is an important trigger of AHR and mucus production, the differences maybe explained by two effects: (i) although the IL-13 levels are significantly lower in the presence of wt SCs, they still reach a concentration of $15 \mathrm{ng} \mathrm{ml}^{-1}$, which seems to be sufficient to drive substantial mucus production; and (ii) AHR is not only regulated by IL-13 but also by IL-17A. In contrast to $\mathrm{C}_{\mathrm{a}} \mathrm{R}^{-1-}$ SCs, administration of wt SCs reduced the IL-17A production from 1.4 to $0.5 \mathrm{ng} \mathrm{ml}^{-1}$ suggesting that the combination of decreased IL13 and IL-17A concentrations caused the decreased AHR in response to wt SCs. The finding that $\mathrm{C}_{\mathrm{a}} \mathrm{R}^{-1-}$ SCs did not block the IL-17A production is in line with our observation that C5aR-deficient BMDCs produce less Th17-inducing cytokines. Despite the high IL-17A levels, we observed a marked decrease in neutrophil numbers. Our data suggest that in an environment with low IL-5 and only a minor number of eosinophils,

\footnotetext{
Figure $8 \mathrm{C} \mathrm{aR}^{-1-} \mathrm{CD} 11 \mathrm{~b}^{\text {hi }} \mathrm{CD} 11 \mathrm{c}^{\text {int }} \mathrm{Gr}-1^{+} \mathrm{F} 4 / 80^{+}$cells suppress $\mathrm{T}$ helper type 2 immune responses in the lung. (a) Experimental design. Briefly, $\mathrm{CD} 11 \mathrm{~b}^{\text {hi }} \mathrm{CD} 11 \mathrm{c}^{\mathrm{int}} \mathrm{Gr}-1^{+} \mathrm{F} 4 / 80^{+}$cells from $\mathrm{C} 5 \mathrm{aR}^{-1-}$ bone marrow (BM) cultures were sorted on day 9 and added to wild-type (wt) BM cultures before incubation with $1 \mu \mathrm{m} \mathrm{DQ}$-OVA or with phosphate-buffered saline for $24 \mathrm{~h}$. The next day, $10^{6}$ unpulsed or pulsed wt $\mathrm{DCs} \pm 3 \times 10^{4} \mathrm{C} 5 \mathrm{aR}{ }^{-1-}$ suppressor cells (SCs) were administered intratracheally (IT) into BALB/c wt recipient mice. After 10 days, mice were challenged IT with ovalbumin (OVA). Seventy-two hours after the injection, airway responsiveness was determined. Subsequently bronchoalveolar lavage (BAL) fluid, lung cells, and tissues were collected for further analysis. BALB/c mice receiving unpulsed cells served as negative controls. Mice that received wt DCs without SCs served as positive controls. (b) Airway hyperresponsiveness (AHR) in response to IT administration of metacholine measured as airway resistance using Flexivent. (c) Total and differential cell counts in BAL fluid. (d) Histological examination of airway inflammation. Sections were stained with hematoxylin and eosin (original magnification $\times 200$ ). (e) Histological examination of goblet cell hyperplasia. Sections were stained with periodic acid-Schiff for mucus production (original magnification $\times 200$ ). Mucus producing airways are plotted relative to all analyzed airways (right panel). (f) Cytokine profiles of pulmonary cells harvested $72 \mathrm{~h}$ after OVA challenge. Supernatants were collected $72 \mathrm{~h}$ after in vitro cell culture. Values shown are the mean $\pm \mathrm{s}$.e.m.; $n=9-10$ per group, ${ }^{\star} P<0.05,{ }^{* *} P<0.01,{ }^{* \star \star} P<0.001$. GM-CSF, granulocyte macrophages colony-stimulating factor; IFN, interferon; IL, interleukin; TNF, tumornecrosis factor.
} 
a

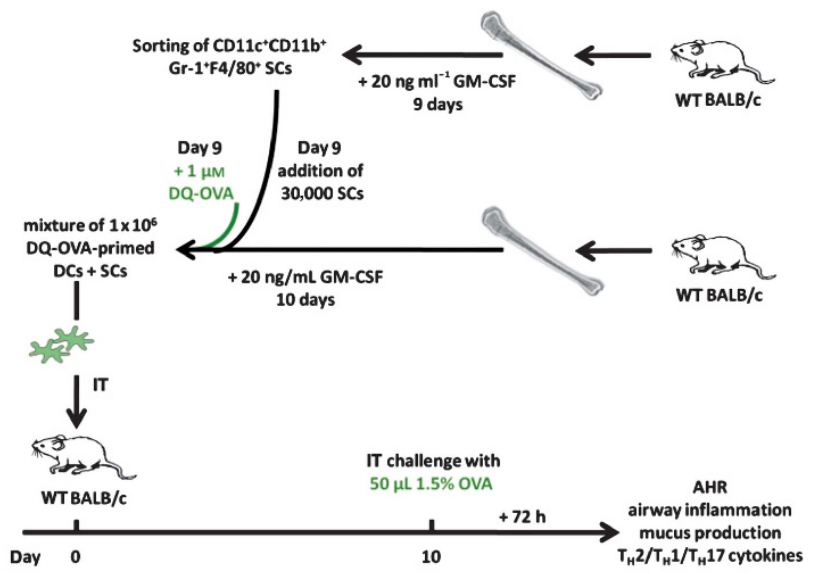

b

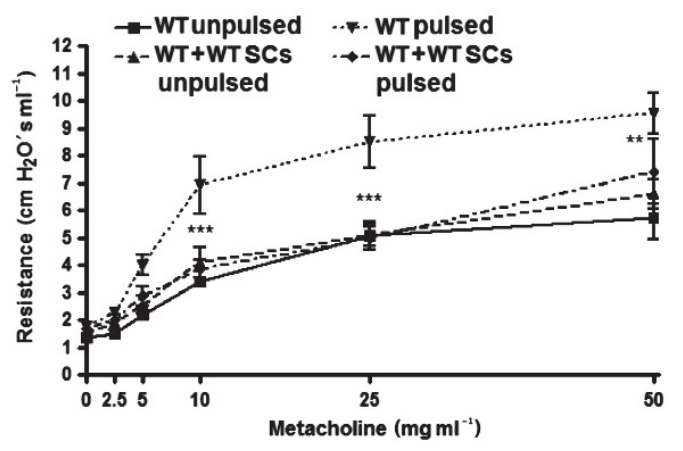

Neutrophils

Lymphocytes
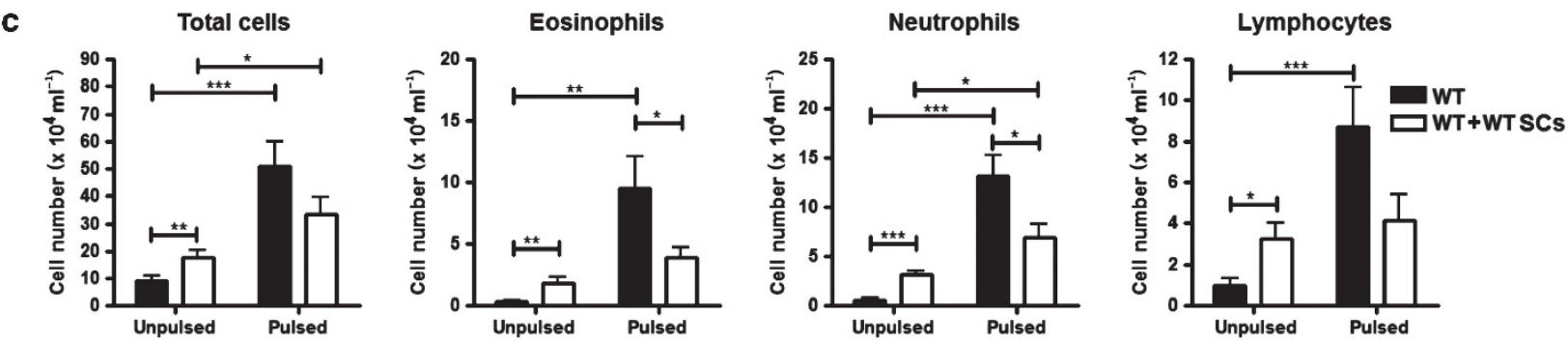

d

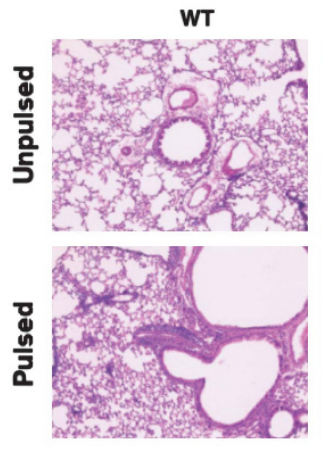

WT+WT SCs
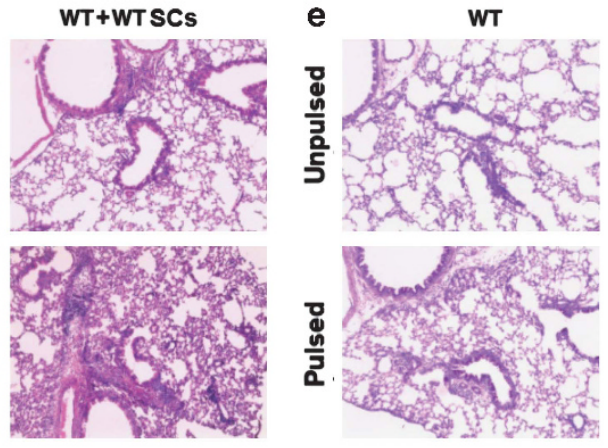

WT+WT SCs
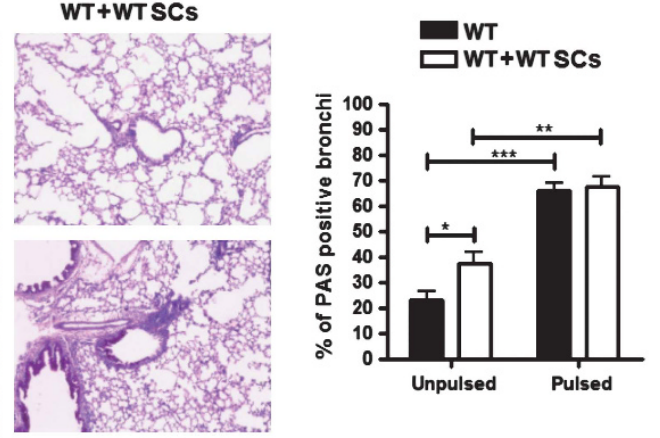

f
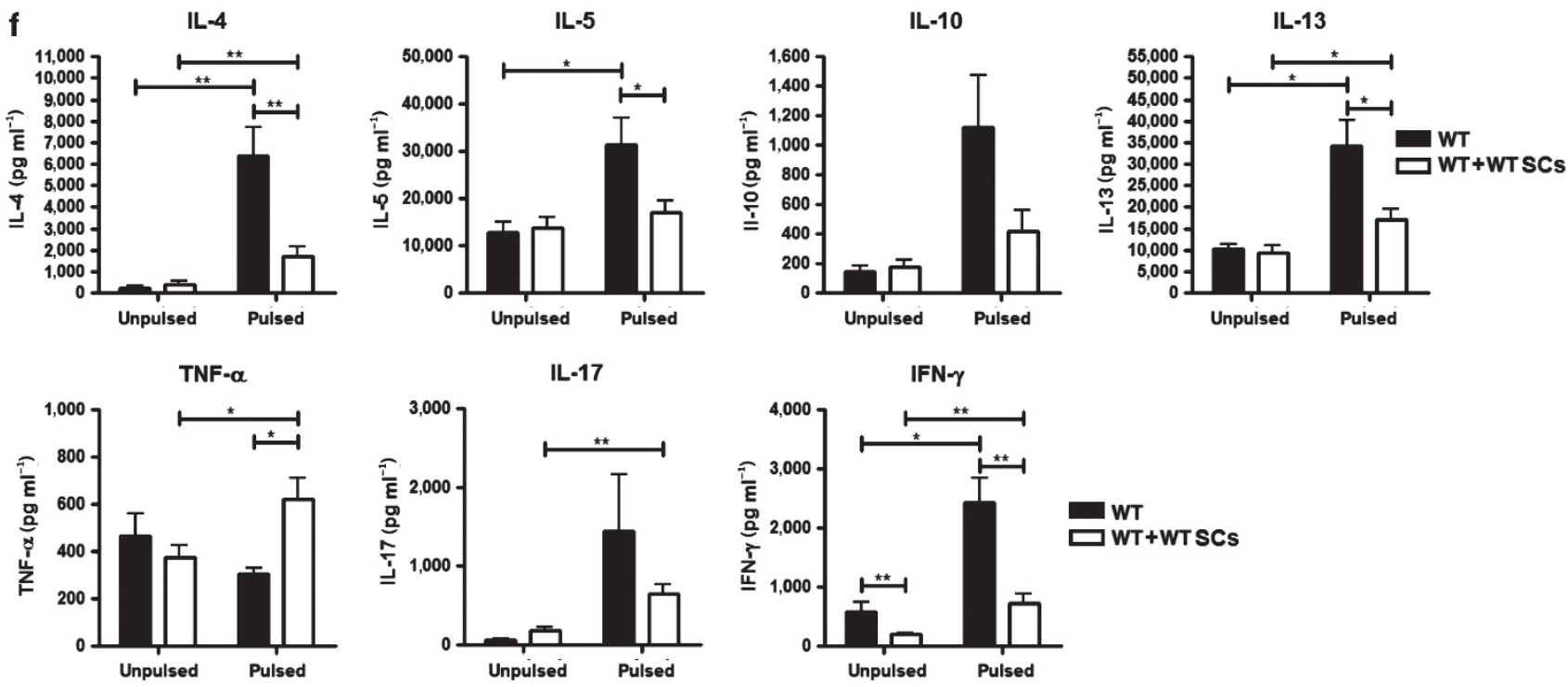
even high IL-17A and TNF- $\alpha$ concentrations ${ }^{32}$ do not drive the accumulation of neutrophils in the airways. This effect might be attributed to the low number of eosinophils as C3a- and C5a-activated eosinophils drive polarization and recruitment of neutrophils. ${ }^{49}$ Another qualitative difference between wt and C5 $\mathrm{aR}^{-1-}$ SCs is that wt but not $\mathrm{C} 5 \mathrm{aR}^{-1-}$ SCs significantly reduced the production of IFN- $\gamma$. Taken together, our findings suggest that the expression of the $\mathrm{C} 5 \mathrm{aR}$ on $\mathrm{BM}$ cells regulates the expansion of a CD11b ${ }^{\text {hi }} \mathrm{CD} 11 \mathrm{c}^{\mathrm{int}} \mathrm{Gr}-1^{+} \mathrm{F} 4 / 80^{+}$SC population. SCs from $\mathrm{C} 5 \mathrm{aR}^{-1-}$ and wt mice exert different abilities to regulate the differentiation of $\mathrm{CD} 4{ }^{+}$Th cells into Th2, Th17, and Th1 cells. Wt SCs exert a broad spectrum of inhibition and can block the differentiation towards Th2, Th17, and Th1 cells. By contrast, $\mathrm{C} 5 \mathrm{aR}^{-1-}$ SCs have lost their ability to block Th1 and Th17 lineage commitment. They are still able to block the production of most Th2 cytokines, including IL-4, IL-5, and IL10 , but they lack the ability to block IL-13 production. In future studies, it will be important to delineate whether $\mathrm{C} 5 \mathrm{aR}$ also controls the expansion and the functional properties of MDSC in the lung in mouse models of experimental allergic asthma that use allergens relevant to human allergy such as HDM, ragweed, or birch pollen.

\section{METHODS}

Mice. BALB/c mice (Charles River, Sulzfeld, Germany), $\mathrm{C} 3 \mathrm{aR}^{-/-}$, $\mathrm{C} 5 \mathrm{~L}^{-1-}$, and $\mathrm{C} 5 \mathrm{aR}^{-1-}$ mice on BALB/c background were bred and maintained in the University of Lübeck specific pathogen-free facility and used at 8-12 weeks of age. Animal care was provided in accordance with German rights. These studies were reviewed and approved by the Schleswig-Holstein state authorities (Nr. V312.72241.122-39).

BMDC preparation and induction of the allergic phenotype in vivo. $\mathrm{BM}$ cells were isolated from naive $\mathrm{BALB} / \mathrm{c}, \mathrm{C} 3 \mathrm{aR}^{-1-}, \mathrm{C} 5 \mathrm{~L} 2^{-/-}$, and $\mathrm{C}_{5} \mathrm{aR}^{-1-}$ mice by flushing femurs and tibias with RPMI medium. Red blood cells were lysed using $155 \mathrm{~mm} \mathrm{NH}_{4} \mathrm{Cl}, 10 \mathrm{~mm} \mathrm{NaHCO}_{3}, 0.1 \mathrm{~mm}$ EDTA (all Sigma-Aldrich, Hamburg, Germany). BM cells $\left(10^{6}\right.$ cells $\left.\mathrm{ml}^{-1}\right)$ were cultured in complete RPMI 1640 culture medium (PAA, Cölbe, Germany) supplemented with 10\% fetal bovine

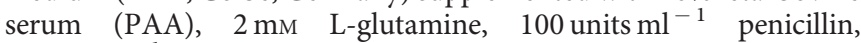
$100 \mu \mathrm{g} \mathrm{ml}^{-1}$ streptomycin (all from GIBCO Invitrogen, Darmstadt, Germany) and $20 \mathrm{ng} \mathrm{ml}^{-1}$ recombinant murine GM-CSF (PeproTech, Hamburg, Germany). Cultures were incubated at $37^{\circ} \mathrm{C}, 5 \% \mathrm{CO}_{2}$ for 10 days. On day 9, cells were pulsed overnight with $1 \mu \mathrm{M}$ DQ-OVA (Invitrogen) in vitro. To induce pulmonary allergy in vivo, DQ-OVApulsed DCs were harvested on day 10 and $10^{6}$ DCs were injected IT into the airways of naive $\mathrm{BALB} / \mathrm{c}$ mice. Recipient mice were challenged IT once after 10 days with $50 \mu 1$ 1.5\% OVA (grade V, Sigma-Aldrich). Unpulsed DCs were injected into $\mathrm{BALB} / \mathrm{c}$ recipients following the same protocol as controls. After $72 \mathrm{~h}$, airway responsiveness was determined and lung tissue samples were harvested for further analysis.

In vivo correlation of antigen uptake/processing and asthma induction. Day-9 wt or C5aR ${ }^{-1-}$ BMDCs $\left(1 \times 10^{6}\right.$ per well $)$ were stimulated with $1 \mu \mathrm{M}$ DQ-OVA in complete RPMI 1640 culture medium (PAA) and $20 \mathrm{ng} \mathrm{ml}^{-1}$ recombinant murine GM-CSF (PeproTech) for $24 \mathrm{~h}$. After staining with anti-CD11c-APC (allophycocyanin) and anti-CD11b-APC-Cy7, CD $11 c^{+} \mathrm{CD}_{11 b^{+} \text {DQ-OVA }}{ }^{\text {hi }}$ cells were separated from the rest of the cells by fluorescence-activated cell sorting using a MoFlo cell sorter (Beckman Coulter, Krefeld, Germany). The sorted DQ-OVQ ${ }^{\text {hi }}$ and DQ-OVA ${ }^{\text {lo }}$ cells were separately transferred into naive BALB/c. On day 10 , mice were challenged with $1.5 \% \mathrm{OVA}$ as above. After $72 \mathrm{~h}$, airway responsiveness was determined, and lung tissue samples were harvested for further analysis.

In vivo assessment of wt and $\mathrm{C}^{5} \mathrm{aR}^{-1-}$ suppressor cell function. Day-9 wt and C5aR ${ }^{-1-}$ BMDCs were stained with anti-CD11c-APC, anti-CD11b-APC-Cy7, anti-F4/80-PE (phycoerythrin) and anti-Gr-1FITC (all eBioscience, Frankfurt, Germany). Cells positive for all the four markers were considered as SCs and sorted using a MoFlo cell sorter. In all, 30,000 SCs were added to $10^{6}$ wt BALB/c DCs and incubated overnight with $1 \mu \mathrm{M}$ DQ-OVA. On day 10 , cells were harvested and adoptively transferred into naive BALB/c. All subsequent immunizations and analyses were performed as described above.

Allergen-induced AHR. AHR was measured in anesthetized mice that were mechanically ventilated using a FlexiVent (SciReq, Montreal, Quebec, Canada). Aerosolized acetyl- $\beta$-methyl-choline (metacholine) $\left(0,1,2.5,5,10,25\right.$, and $50 \mathrm{mg} \mathrm{ml}^{-1}$; Sigma-Aldrich) was generated by an ultrasonic nebulizer and delivered in-line through the inhalation port for $10 \mathrm{~s}$. Airway resistance was measured 2 min later.

Collection of blood and bronchoalveolar lavage fluid. Bronchoalveolar lavage samples were obtained as described. ${ }^{6}$ Differential cell counts of bronchoalveolar lavage cells were obtained after spinning the cells down onto slides and staining with May-Grünwald-Giemsa stain (Sigma-Aldrich). A minimum of 200 cells were morphologically differentiated by light microscopy.

Isolation of pulmonary cells and cytokine measurements. Collagenase/DNase I (both Sigma-Aldrich) digests of the lungs were prepared to obtain single lung cell suspensions. ${ }^{6}$ Single-cell suspensions $\left(2.5 \times 10^{5}\right)$ were restimulated ex vivo with $1 \mu \mathrm{M}$ OVA or with medium alone, and incubated at $37^{\circ} \mathrm{C}$ for $72 \mathrm{~h}$ in complete RPMI 1640 culture medium. Production of interleukin (IL)-4, IL-5, IL-10, IL-13, IL-17A, IFN- $\gamma$, and TNF- $\alpha$ in culture supernatants was determined using DuoSet ELISA kits (R\&D Systems, Wiesbaden, Germany) following the manufacturer's protocol. The sensitivities were $16 \mathrm{pg} \mathrm{ml}^{-1}$ for IL-4 and IL-17A, $31 \mathrm{pg} \mathrm{ml}^{-1}$ for IL-5, IL-10, IFN- $\gamma$, and TNF- $\alpha$, and $62.5 \mathrm{pg} \mathrm{ml}^{-1}$ for IL-13.

Lung histology. Lung histological staining, detection, and quantification of mucus cell content were done as described. ${ }^{48}$ Briefly, lungs

Figure $9 \mathrm{CD} 11 \mathrm{~b}^{\mathrm{hi}} \mathrm{CD} 11 \mathrm{c}^{\mathrm{int}} \mathrm{Gr}-1^{+} \mathrm{F} 4 / 80^{+}$suppressor cells (SCs) from wild-type (wt) mice suppress $\mathrm{T}$ helper type 2 (Th2), Th17, and Th1 immune responses in the lung. (a) Experimental design. Briefly, CD $11 b^{\text {hi }} C D 11 c^{\text {int }} G r-1^{+} F 4 / 80^{+}$cells from wt bone marrow (BM) cultures were sorted on day 9 and added to wt BM-cultures before incubation with $1 \mu \mathrm{M} \mathrm{DQ-OVA}$ or with phosphate-buffered salinefor $24 \mathrm{~h}$. The next day, $10^{6} \mathrm{unpulsed}$ or pulsed wt DCs $\pm 3 \times 10^{4}$ wt SCs were administered intratracheally (IT) into BALB/c wt recipient mice. After 10 days, mice were challenged IT with ovalbumin (OVA). Seventy-two hours after the injection, airway responsiveness was determined. Subsequently bronchoalveolar lavage (BAL) fluid, lung cells and tissues were collected for further analysis. BALB/c mice receiving unpulsed cells served as negative controls. Mice that received wt DCs without SCs served as positive controls. (b) Airway hyperresponsiveness (AHR) in response to IT administration of metacholine measured as airway resistance using Flexivent. (c) Total and differential cell counts in BAL fluid. (d) Histological examination of airway inflammation. Sections were stained with hematoxylin and eosin (original magnification $\times 200$ ). (e) Histological examination of goblet cell hyperplasia. Sections were stained with periodic acid-Schiff for mucus production (original magnification $\times 200$ ). Mucus producing airways are plotted relative to all analyzed airways (right panel). (f) Cytokine profiles of pulmonary cells harvested $72 \mathrm{~h}$ after OVA challenge. Supernatants were collected $72 \mathrm{~h}$ after in vitro cell culture. Values shown are the mean \pm s.e.m.; $n=9$-10 per group, ${ }^{*} P<0.05$, ${ }^{* *} P<0.01$, ${ }^{* * *} P<0.001$. GM-CSF, granulocyte macrophages colony-stimulating factor; IFN, interferon; IL, interleukin; TNF, tumor-necrosis factor. 
were excised and fixed in $3.7 \%$ formalin. Fixed tissues were then washed with $70 \%$ ethanol, dehydrated, embedded in paraffin, and cut into $5 \mu \mathrm{m}$ sections. Slides were stained with hematoxylin and eosin and periodic acid-Schiff (PAS). For quantification of mucus production in the airway epithelium, PAS positive and PAS negative airways were counted by light microscopy from four lung sections per animal.

In vitro analysis of antigen uptake and processing. Day-10 wt, $\mathrm{C}_{3} \mathrm{aR}^{-1-}, \mathrm{C} 5 \mathrm{~L} 2^{-1-}$ or $\mathrm{C} 5 \mathrm{aR}^{-1-}$ BMDCs $\left(10^{6} /\right.$ well $)$ were stimulated with DQ- or FITC-OVA, $10 \mu \mathrm{g} \mathrm{ml}^{-1}$, in complete RPMI 1640 culture medium (PAA) for $0,15,30,60,90,120,180$, or $240 \mathrm{~min}$ at 37 or $4{ }^{\circ} \mathrm{C}$ as a control. Uptake and processing were detected in the FITCchannel after staining with anti-CD11c-APC and anti-CD11b-APCCy7 on a BD-LSRII (Becton Dickinson, Heidelberg, Germany). To analyze pinocytosis or scavenger receptor-mediated endocytosis, cells were incubated with dimethylamiloride $(500 \mu \mathrm{M}$, Sigma-Aldrich) or poly-inosinic acid (144 $\mu \mathrm{m}$, Sigma-Aldrich) $30 \mathrm{~min}$ before incubation with FITC-/DQ-OVA as described previously. ${ }^{16}$

In vitro stimulation of BMDCs. Wt or $\mathrm{C}^{2} \mathrm{aR}^{-1-} \mathrm{BMDCs}\left(1 \times 10^{6}\right.$ per well; day 9) were stimulated with DQ or FITC-OVA, $1 \mu \mathrm{M}$, in complete RPMI 1640 culture medium) and $20 \mathrm{ng} \mathrm{ml}^{-1}$ recombinant murine GMCSF (PeproTech) at $37^{\circ} \mathrm{C}$ for $24 \mathrm{~h}$. Secretion of IL-1 $\beta$, IL-6, IL-12p40, IL$12 \mathrm{p} 70$, IL-23, and TGF- $\beta$ in culture supernatants was determined using DuoSet ELISA kits (R\&D Systems) following the manufacturer's protocol. The sensitivities were $16 \mathrm{pg} \mathrm{ml}^{-1}$ for IL-1 $\beta$, IL-6, IL-12p 40 , and IL-33, $31 \mathrm{pg} \mathrm{ml}^{-1}$ for TGF- $\beta$, and $39 \mathrm{pg} \mathrm{ml}^{-1}$ for IL-23 and IL-12p70. Expression of surface markers was analyzed using anti-CD11c-APC, anti-CD11b-APC-Cy7, anti-MHC-II-PE, anti-CD80-biotin conjugated to Qdot 585, anti-CD86-biotin conjugated to Qdot 655 and anti-CD40biotin conjugated to Qdot 585 (all antibodies from eBiosciences, Qdots from Invitrogen) on a BD LSRII (Becton Dickinson).

Phenotypic characterization of $\mathrm{CD}_{11} \mathrm{~b}^{\text {hi }} \mathrm{CD} 11 \mathrm{c}^{\text {int }} \mathrm{Gr}-\mathbf{1}^{+} \mathrm{F} 4 / 80^{+}$ cells. Day-9 BMDCs were stained with anti-CD11c-APC, antiCD11b-APC-Cy7 and anti-Gr-1-Pacific blue, anti F4/80-PE (all from eBioscience). Cells expressing CD11c, CD11b, F4/80, and Gr-1 with a high SSC (side scatter) were classified as SCs. The morphology of sorted $\mathrm{CD} 11 \mathrm{c}^{+} \mathrm{CD} 11 \mathrm{~b}^{+} \mathrm{Gr}-1^{+} \mathrm{F} 4 / 80^{+}$cells was evaluated by MayGrünwald-Giemsa staining (Sigma-Aldrich) using light microscopy.

Functional characterization of $\mathrm{CD} 11 \mathrm{~b}^{\text {hi }} \mathrm{CD} 11 \mathrm{C}^{\text {int }} \mathrm{Gr}-1^{+} \mathrm{F} 4 / 80^{+}$cells. Day-9 BM cells were stained with anti-CD11c-APC, anti-CD11bAPC-Cy7, anti-Gr-1-FITC, and anti-F4/80-PE (all from eBioscience). Cells positive for all four markers were considered as SCs and sorted using a MoFlo cell sorter. SCs were cultured in complete RPMI 1640 for $24 \mathrm{~h}$ at $37^{\circ} \mathrm{C}$ and $5 \% \mathrm{CO}_{2}$. Expression levels for arginase 1 and NOS2 were evaluated by RT-PCR in resting cells or after stimulation with $50 \mathrm{ng} \mathrm{ml}^{-1}$ IL-4 (R\&D Systems).

RNA isolation and real-time PCR. RNA was isolated using Trizol reagent according to the manusfacturer's instructions (Invitrogen). Reverse transcription reaction was performed after DNAse I treatment of the RNA (Fermentas, Thermo Fisher Scientific Inc., Waltham, MA) using first strand cDNA synthesis kit (Revertaid Premium, Fermentas). Quantitative PCR was done using iQ Sybr green (Bio-rad, München, Germany) on a IQ iCycler PCR machine (Bio-rad) using the following primers (Eurofins, Reichenwalde, Germany): actin $5^{\prime}$ GCACCACACCTTCTACAATGAG-3' (sense) and 5'-AAATAGCA CAGCCTGGATAGCAAC- $3^{\prime}$ (antisense), arginase $15^{\prime}$-AACACGG CAGTG GCTTTAACC- $3^{\prime}$ (sense) and $5^{\prime}$-GGTTTTCATGTGGCGC ATTC-3' (antisense), NOS2 5'-AGCCAAGCCCTCACCTAC-3 ${ }^{\prime}$ (sense) and $5^{\prime}$-AATCTCTGCCTATCCGTC-3' (antisense), Bcl2 $5^{\prime}$ GTCGCTACCGTCGTGACTTC-3' (sense) and $5^{\prime}$-CAGACATGCA CCTACCCAGC-3' (antisense), BCL-X ${ }_{\mathrm{L}} 5^{\prime}$-TTCGGGATGGAGTAA ACTGGG-3' (sense) and $5^{\prime}$-AGTCATGCCCGTCCACAAAA-3' (antisense), BimL 5' - GACAGAACCGCAAGACAGGAG-3' (sense) and $5^{\prime}$-GGACTTGGGGTTTGTGTTGAC-3' (antisense), BimEL $5^{\prime}$ GACAGAACCGCAAGGTAATCC-3' (sense) and 5'-ACTTGTCACA
ACTCATGGGTG-3' (antisense), and Bbc3 (PUMA) 5'-ACCTCAAC GCGCAGTACGAGC-3' (sense) and 5'-GAAGAGATTGTACATGAC CCT-3' (antisense).

Co-culture of BMDCs with OVA-TCR transgenic T cells and T-cell proliferation assay. Day-9 BMDCs were harvested, seeded at a density of $2 \times 10^{4}$ cells $/ 200 \mu \mathrm{l}$ in a 96-well plate, and stimulated overnight with OVA $\left(10 \mu \mathrm{M}\right.$, grade V, Sigma-Aldrich). The next day, naive CD4 ${ }^{+} \mathrm{T}$ cells from OVA-TCR transgenic DO11.10/RAG2 ${ }^{-1-}$ mice were isolated from spleen by magnetic selection using the CD4 isolation kit II (Miltenyi, Bergisch-Gladbach, Germany) according to the manufacturer's instructions, labeled with CFSE $(1 \mu \mathrm{M}$; Molecular Probes, Darmstadt, Germany), and $1 \times 10^{5}$ cells were co-cultured with BMDCs from wt or $\mathrm{C} 5 \mathrm{aR}^{-1-}$ mice. Four days later, cells were harvested, stained with anti-CD4-APC (eBioscience), and assessed for cell proliferation by flow cytometry on a BD LSRII (Becton Dickinson) and for cytokine production by ELISA. Analyzed cytokines were IL-4, IL-5, IL-10, IL-13, IL-17, and IFN- $\gamma$ (detection limits are indicated above, all DuoSets from R\&D Systems). Further, on day 7, IL-2 levels were assessed by ELISA (detection limit $16 \mathrm{pg} \mathrm{ml}^{-1}$, DuoSet R\&D Systems), cell survival was evaluated by staining cells with anti-CD4APC and $3 \mu \mathrm{M}$ DAPI (Sigma), and RNA was isolated to analyze pro/ anti-apoptotic molecules by real-time PCR as described previously. ${ }^{50}$

In vivo expansion of OVA-TCR transgenic $\mathrm{T}$ cells by wt and C5aR $^{-1-}$ DCs. OVA-specific CD $4^{+} \mathrm{T}$ cells were purified from the spleens of DO11.10/Rag2 ${ }^{-1-}$ mice by magnetic-activated cell sorting using the CD4 isolation kit II (Miltenyi) according to the manufacturer's instructions. Purified T cells were labeled with CFSE ( $1 \mu \mathrm{M}$; Molecular Probes) and $5 \times 10^{5}$ cells were intravenously injected into wt recipient mice. After $24 \mathrm{~h}, 1 \times 10^{6}$ BMDCs, stimulated for $24 \mathrm{~h}$ with $1 \mu \mathrm{M}$ DQ-OVA (Molecular Probes), were harvested, washed with phosphate-buffered saline, and IT transferred into wt recipient mice. Five or nine days later, mice were killed, and the lung and lymph nodes were excised. Collagenase/DNase I (both Sigma-Aldrich) digests of the lungs were prepared to obtain single lung cell suspensions. To determine the frequency of OVA-specific $\mathrm{CD} 4{ }^{+} \mathrm{T}$ cells in the lung and the lymph nodes, cells were stained with APC-labeled DO11.10 TCRspecific antibody KJ-126 (eBiosciences) and analyzed by flow cytometry.

Statistical analysis. Statistical analysis was performed using the GraphPad Prism version 4 (GraphPad Software, La Jolla, CA). Statistical differences were evaluated by either ANOVA, paired or unpaired $t$-test. $P$-values $<0.05$ were considered statistically significant.

SUPPLEMENTARY MATERIAL is linked to the online version of the paper at http://www.nature.com/mi

\section{ACKNOWLEDGEMENTS}

This work has been support by Deutsche Forschungsgemeinschaft (DFG) grant TR/SFB 22 project A21 to J.K.

\section{DISCLOSURE}

The authors declared no conflict of interest.

(c) 2013 Society for Mucosal Immunology

\section{REFERENCES}

1. Lambrecht, B.N. \& Hammad, H. Lung dendritic cells in respiratory viral infection and asthma: from protection to immunopathology. Annu. Rev. Immunol. 30, 243-270 (2012).

2. Raymond, M. et al. Selective control of SIRP-alpha-positive airway dendritic cell trafficking through CD47 is critical for the development of $\mathrm{T}(\mathrm{H}) 2$-mediated allergic inflammation. J. Allergy Clin. Immunol. 124, 1333-1342 (2009). 
3. Furuhashi, K. et al. Mouse lung CD103 + and CD11bhigh dendritic cells preferentially induce distinct CD4 + T-cell responses. Am. J. Respir. Cell Mol. Biol. 46, 165-172 (2012).

4. Nakano, H. et al. Pulmonary $\mathrm{CD} 103(+)$ dendritic cells prime Th2 responses to inhaled allergens. Mucosal Immunol. 5, 53-65 (2012).

5. De Heer, H.J. et al. Essential role of lung plasmacytoid dendritic cells in preventing asthmatic reactions to harmless inhaled antigen. J. Exp. Med. 200, 89-98 (2004).

6. Köhl, J. et al. A regulatory role for the C5a anaphylatoxin in type 2 immunity in asthma. J. Clin. Invest. 116, 783-796 (2006).

7. Zhang, X. \& Köhl, J. A complex role for complement in allergic asthma. Expert Rev. Clin. Immunol. 6, 269-277 (2010).

8. Krug, N., Tschernig, T., Erpenbeck, V.J., Hohlfeld, J.M. \& Köhl, J. Complement factors $\mathrm{C} 3 \mathrm{a}$ and $\mathrm{C} 5 \mathrm{a}$ are increased in bronchoalveolar lavage fluid after segmental allergen provocation in subjects with asthma. Am. J. Respir. Crit. Care Med. 164, 1841-1843 (2001).

9. Lajoie, S. et al. Complement-mediated regulation of the IL-17A axis is a central genetic determinant of the severity of experimental allergic asthma. Nat. Immunol. 11, 928-935 (2010).

10. Karp, C.L. et al. Identification of complement factor 5 as a susceptibility locus for experimental allergic asthma. Nat. Immunol. 1, 221-226 (2000).

11. Drouin, S.M., Sinha, M., Sfyroera, G., Lambris, J.D. \& Wetsel, R.A. A protective role for the fifth complement component (c5) in allergic airway disease. Am. J Respir. Crit. Care Med. 173, 852-857 (2006).

12. Baelder, R. et al. Pharmacological targeting of anaphylatoxin receptors during the effector phase of allergic asthma suppresses airway hyperresponsiveness and airway inflammation. J. Immunol. 174, 783-789 (2005).

13. Abe, M. et al. Contribution of anaphylatoxin C5a to late airway responses after repeated exposure of antigen to allergic rats. J. Immunol. 167, 4651-4660 (2001).

14. Zhang, $\mathrm{X}$. et al. A protective role for $\mathrm{C} 5 \mathrm{a}$ in the development of allergic asthma associated with altered levels of $\mathrm{B} 7-\mathrm{H} 1$ and $\mathrm{B} 7-\mathrm{DC}$ on plasmacytoid dendritic cells. J. Immunol. 182, 5123-5130 (2009).

15. Weaver, D.J. Jr et al. C5a receptor-deficient dendritic cells promote induction of Treg and Th17 cells. Eur. J. Immunol. 40, 710-721 (2010).

16. Burgdorf, S., Kautz, A., Bohnert, V., Knolle, P.A. \& Kurts, C. Distinct pathways of antigen uptake and intracellular routing in CD4 and CD8 Tcell activation. Science 316, 612-616 (2007).

17. Lambrecht, B.N. et al. Myeloid dendritic cells induce Th2 responses to inhaled antigen, leading to eosinophilic airway inflammation. J. Clin. Invest. 106, 551-559 (2000).

18. Sung, S., Rose, C.E. \& Fu, S.M. Intratracheal priming with ovalbumin- and ovalbumin 323-339 peptide-pulsed dendritic cells induces airway hyperresponsiveness, lung eosinophilia, goblet cell hyperplasia, and inflammation. J. Immunol. 166, 1261-1271 (2001).

19. Raymond, M., Van, V.Q., Wakahara, K., Rubio, M. \& Sarfati, M. Lung dendritic cells induce $T(H) 17$ cells that produce $T(H) 2$ cytokines, express GATA-3, and promote airway inflammation. J. Allergy Clin. Immunol. 128 , 192-201 e196 (2011).

20. Strainic, M.G. et al. Locally produced complement fragments C5a and C3a provide both costimulatory and survival signals to naive CD4 $+T$ cells. Immunity 28, 425-435 (2008).

21. Peng, Q. et al. Dendritic cell function in allostimulation is modulated by C5aR signaling. J. Immunol. 183, 6058-6068 (2009).

22. Bouillet, P. \& O'Reilly, L.A. CD95, BIM and T cell homeostasis. Nat. Rev. Immunol. 9, 514-519 (2009).

23. Erlacher, M. et al. Puma cooperates with Bim, the rate-limiting BH3-only protein in cell death during lymphocyte development, in apoptosis induction. J. Exp. Med. 203, 2939-2951 (2006).

24. Gabrilovich, D.I. \& Nagaraj, S. Myeloid-derived suppressor cells as regulators of the immune system. Nat. Rev. Immunol. 9, 162-174 (2009).

25. Youn, J.I., Nagaraj, S., Collazo, M. \& Gabrilovich, D.I. Subsets of myeloid-derived suppressor cells in tumor-bearing mice. J. Immunol. 181, 5791-5802 (2008).

26. Marigo, I., Dolcetti, L., Serafini, P., Zanovello, P. \& Bronte, V. Tumor-induced tolerance and immune suppression by myeloid derived suppressor cells. Immunol. Rev. 222, 162-179 (2008).
27. Greifenberg, V., Ribechini, E., Rossner, S. \& Lutz, M.B. Myeloid-derived suppressor cell activation by combined LPS and IFN-gamma treatment impairs DC development. Eur. J. Immunol. 39, 2865-2876 (2009).

28. Arora, M. et al. TLR4/MyD88-induced CD11b + Gr-1 int F4/80 + nonmigratory myeloid cells suppress Th2 effector function in the lung. Mucosal Immunol. 3, 578-593 (2010).

29. Hawlisch, H. et al. C5a negatively regulates toll-like receptor 4-induced immune responses. Immunity 22, 415-426 (2005).

30. Fang, C., Zhang, X., Miwa, T. \& Song, W.C. Complement promotes the development of inflammatory T-helper 17 cells through synergistic interaction with Toll-like receptor signaling and interleukin-6 production. Blood 114, 1005-1015 (2009).

31. McKinley, L. et al. TH17 cells mediate steroid-resistant airway inflammation and airway hyperresponsiveness in mice. J. Immunol. 181, 4089-4097 (2008).

32. Fei, M. et al. TNF-alpha from inflammatory dendritic cells (DCs) regulates lung IL-17A/IL-5 levels and neutrophilia versus eosinophilia during persistent fungal infection. Proc. Natl. Acad. Sci. USA 108, 5360-5365 (2011).

33. Krishnamoorthy, N. et al. Activation of c-Kit in dendritic cells regulates $T$ helper cell differentiation and allergic asthma. Nat. Med. 14, 565-573 (2008).

34. Shushakova, N. et al. C5a anaphylatoxin is a major regulator of activating versus inhibitory FcgammaRs in immune complex-induced lung disease. J. Clin. Invest. 110, 1823-1830 (2002).

35. Drouin, S.M. et al. Expression of the complement anaphylatoxin C3a and C5a receptors on bronchial epithelial and smooth muscle cells in models of sepsis and asthma. J. Immunol. 166, 2025-2032 (2001).

36. Zhang, X. et al. A critical role for C5L2 in the pathogenesis of experimental allergic asthma. J. Immunol. 185, 6741-6752 (2010).

37. Korn, T., Bettelli, E., Oukka, M. \& Kuchroo, V.K. IL-17 and Th17 cells. Annu. Rev. Immunol. 27, 485-517 (2009).

38. Hashimoto, M. et al. Complement drives Th17 cell differentiation and triggers autoimmune arthritis. J. Exp. Med. 207, 1135-1143 (2010).

39. Liu, B. et al. Complement component C5a promotes expression of IL-22 and IL-17 from human T cells and its implication in age-related macular degeneration. J. Transl. Med. 9, 1-12 (2011).

40. Li, K. et al. Cyclic AMP plays a critical role in C3a-receptor-mediated regulation of dendritic cells in antigen uptake and T-cell stimulation. Blood 112, 5084-5094 (2008).

41. Sallusto, F., Cella, M., Danieli, C. \& Lanzavecchia, A. Dendritic cells use macropinocytosis and the mannose receptor to concentrate macromolecules in the major histocompatibility complex class II compartment: downregulation by cytokines and bacterial products. J. Exp. Med. 182, 389-400 (1995).

42. Menges, M. et al. IL-4 supports the generation of a dendritic cell subset from murine bone marrow with altered endocytosis capacity. J. Leukoc. Biol. 77, 535-543 (2005).

43. Yamane, H., Zhu, J. \& Paul, W.E. Independent roles for IL-2 and GATA-3 in stimulating naive CD4 + T cells to generate a Th2-inducing cytokine environment. J. Exp. Med. 202, 793-804 (2005).

44. Lalli, P.N. et al. Locally produced C5a binds to T cell-expressed C5aR to enhance effector T-cell expansion by limiting antigen-induced apoptosis 153. Blood 112, 1759-1766 (2008).

45. Deshane, J. et al. Free radical-producing myeloid-derived regulatory cells: potent activators and suppressors of lung inflammation and airway hyperresponsiveness. Mucosal Immunol. 4, 503-518 (2011).

46. Rossner, S. et al. Myeloid dendritic cell precursors generated from bone marrow suppress $T$ cell responses via cell contact and nitric oxide production in vitro. Eur. J. Immunol. 35, 3533-3544 (2005).

47. Markiewski, M.M. et al. Modulation of the antitumor immune response by complement. Nat. Immunol. 9, 1225-1235 (2008).

48. Wills-Karp, M. et al. Interleukin-13: central mediator of allergic asthma. Science 282, 2258-2261 (1998).

49. Daffern, P.J., Pfeifer, P.H., Ember, J.A. \& Hugli, T.E. C3a is a chemotaxin for human eosinophils but not for neutrophils. I. C3a stimulation of neutrophils is secondary to eosinophil activation. J. Exp. Med. 181, 2119-2127 (1995).

50. Hildeman, D.A. et al. Activated Tcell death in vivo mediated by proapoptotic bcl-2 family member bim. Immunity 16, 759-767 (2002). 